\title{
Promoting Healthier Drinking Habits: Using Sound to Encourage the Choice for Non-Alcoholic Beers in E-Commerce
}

\author{
Brayan Rodríguez ${ }^{1,2}\left(\mathbb{D}\right.$, Christian Arroyo ${ }^{3}$, Luis H. Reyes ${ }^{4}(\mathbb{D})$ and Felipe Reinoso-Carvalho ${ }^{5, *}$ \\ 1 School of Engineering, Universidad del Valle, Cali 760001, Colombia; \\ brayan.rodriguez.rivera@correounivalle.edu.co \\ 2 School of Engineering, Universidad de los Andes, Bogotá 111711, Colombia \\ 3 School of Marketing and Innovation, Muma College of Business, University of South Florida, \\ Tampa, FL 33620, USA; arroyomera@usf.edu \\ 4 Grupo de Diseño de Productos y Procesos, Department of Chemical and Food Engineering, Universidad de \\ los Andes, Bogotá 111711, Colombia; lh.reyes@uniandes.edu.co \\ 5 School of Management, Universidad de los Andes, Bogotá 111711, Colombia \\ * Correspondence: f.reinosoc@uniandes.edu.co
}

Citation: Rodríguez, B.; Arroyo, C.; Reyes, L.H.; Reinoso-Carvalho, F. Promoting Healthier Drinking Habits: Using Sound to Encourage the Choice for Non-Alcoholic Beers in E-Commerce. Foods 2021, 10, 2063. https://doi.org/10.3390/foods1009 2063

Received: 7 July 2021

Accepted: 18 August 2021

Published: 1 September 2021

Publisher's Note: MDPI stays neutral with regard to jurisdictional claims in published maps and institutional affiliations.

Copyright: (C) 2021 by the authors. Licensee MDPI, Basel, Switzerland. This article is an open access article distributed under the terms and conditions of the Creative Commons Attribution (CC BY) license (https:// creativecommons.org/licenses/by/ $4.0 /)$.

\begin{abstract}
Important institutions, such as the World Health Organization, recommend reducing alcohol consumption by encouraging healthier drinking habits. This could be achieved, for example, by employing more effective promotion of non-alcoholic beverages. For such purposes, in this study, we assessed the role of experiential beer packaging sounds during the e-commerce experience of a non-alcoholic beer (NAB). Here, we designed two experiments. Experiment 1 evaluated the influence of different experiential beer packaging sounds on consumers' general emotions and sensory expectations. Experiment 2 assessed how the sounds that evoked more positive results in Experiment 1 would influence emotions and sensory expectations related to a NAB digital image. The obtained results revealed that a beer bottle pouring sound helped suppress some of the negativity that is commonly associated with the experience of a NAB. Based on such findings, brands and organizations interested in more effectively promoting NAB may feel encouraged to involve beer packaging sounds as part of their virtual shopping environments.
\end{abstract}

Keywords: beer; e-commerce; food marketing; multisensory experiences; non-alcoholic beer; sound; expectations

\section{Introduction}

With beer being one of the most popular drinks [1] and consumers (particularly the youngest) demanding healthier beverage alternatives to moderate their alcohol intake, the sales of non-alcoholic beer (NAB) have steadily risen in recent years [2]. The global NAB market is predicted to grow by around $24 \%$ yearly by the end of 2021 . Such a market is expected to have an accumulated value greater than US \$29 billion by 2026 [3], showing its strategic and progressive importance in the beverages sector. Such increase in value is, among other things, due to the growing awareness of consumers when it comes to the health risks associated with alcohol consumption. For example, in 2019, it was reported that $47 \%$ of consumers limited their alcohol consumption compared to 12 months earlier [4]. However, and even though NAB consumption is growing fast compared to alcoholic beers, NAB market share is still negligible [5-7].

The World Health Organization (WHO) encourages a shift in consumer attitudes by thoroughly and widely exposing the harms of alcohol consumption abuse. Such abuse causes approximately 3 million deaths each year worldwide, while also contributing to diverse disabilities and poor health of millions of consumers. Overall, the abuse of alcohol consumption is responsible for more than $5 \%$ of the global burden of disease [8]. Consequently, the WHO is somehow calling attention to the growing need to reduce 
alcoholic drinks' consumption. Since beer is consistently one of the most consumed beverages globally, nudging consumers to choose the alcohol-free version of a beer while shopping may be an effective way to reduce alcohol consumption. In this sense, a NAB is produced with the same raw materials as an alcoholic beer, which provides a range of similar experiential sensory cues that may be useful to prime the consumer during beer-related decision-making tasks [9]. Hence, to improve the acceptability of NAB while fomenting healthier drinking habits, in this study, we proposed to nudge consumers towards more effectively choosing $\mathrm{NAB}$ while shopping for drinks. For this, we focused on modulating their emotions and sensory expectations associated with a NAB via digital and multisensory customization.

\section{Theoretical Framework}

There is scarce research on which variables influence NAB emotions and sensory expectations. For instance, evidence suggests that a NAB is usually perceived as a functional substitute for alcoholic beverages and not a hedonic one [10]. The latter study showed that while being consumed, a NAB mostly evoked neutral or negative emotional responses compared to the emotions elicited by an alcoholic beer or a wine. Meanwhile, in 2017, Silva et al. [11] conducted another study on how two product names, "beer" and "NAB," might affect such products' conceptualizations and, thus, consumers' responses. Here, participants consumed labeled alcoholic beer and NAB in a café/bar, and in some cases, these drinks were mislabeled. The obtained results indicated that the label "NAB" itself was systematically associated with negative emotions (sadness, disappointment, irritability). On the contrary, positive emotions, such as amused, joyful, and excited, were commonly associated with the product labeled "beer." In other words, both studies mentioned above revealed that a NAB might constantly be framed as a product associated with negativity by consumers. In fact, according to Blackmore et al. [12], non-alcohol and low-alcohol content on beer labels tend to be associated with sensory expectations related to negative beer tasting experiences, such as an excessive sweetness, lack of bitterness, and a light body.

Note that the studies mentioned earlier only focused on the influence of visual and/or flavor sensory cues. However, consumer perception has been extensively discussed as inherently multisensorial [13], where sounds could play a crucial role in consumption decision-making tasks. Although product design and multisensory marketing are growing research fields [14], to the best of our knowledge, there is little research on the role of sonic cues on expectations and/or emotions related to NAB experiences.

Packaging sounds are more and more considered as added-value during a purchase experience. Several brands increasingly use sounds to distinguish themselves from the competition while communicating functional expectations about products [15]. Indeed, people can discern the viscosity, carbonation, and temperature of a beverage just by hearing its pouring sound [16]. Therefore, producers of healthy and dietetic foods could also consider using sounds to more effectively promote this kind of value proposition associated with their products, such as lower alcohol/calories/fat/sugar/salt. In line with the above, we decided to encourage NAB consumption by employing experiential beer packaging sounds in a multisensory shopping context.

A very recent study employed experiential beer packaging sounds to assess beer "premiumness" [17]. Here, the participants listened to opening and pouring beer sounds from a bottle and a can at different sound pressure levels and frequency ranges. They found evidence that the participants perceived the opening sounds of bottles as more premium than those of cans, and the pouring sounds as more premium than the opening ones. Moreover, they also found that the louder opening sounds were perceived as more premium than the quieter ones. This recent study also showed that the more a sound was associated with a premium beer, the more alive, good, pleasant, and happy the participants evaluated it. As a complement, and concerning hedonic sensations associated with high audible frequency ranges (i.e., pitch), another study also reported that high-pitched product 
opening sounds were more associated with somewhat positive concepts, such as brisk, comfortable, and secure [18].

Considering the aforementioned, and together with the fact that customers spend increasing amounts of time shopping and researching for products online [19], it may be useful for retailers to rely on multisensory product cues as part of digital marketplace experiences, such as packaging sounds. Hence, we decided to frame this new study within the scope of e-commerce experiences. In this context, Ringler et al. [20] recently explored how the sounds generated by the regular operation of a product, while coupled with corresponding imagery (in a screen or utilizing a virtual reality experience), would encourage customers to focus on the product in use and ultimately enhance their willingness to pay. In such a context, they found that louder sounds (vs. quieter) positively affected the perceived product's power and improved the willingness to pay for it.

Sounds are undoubtedly rich in information while evoking product expectations and emotional responses towards products. However, their use in digital retailing spaces remains limited, highlighting a disconnection between marketing theorists and practitioners [21,22]. Hence, we believe that more research is needed on the role of sound on consumers' behavior in e-commerce experiences. It is acknowledged that sounds placed on e-commerce create positive feedback from consumers [23]. For instance, research suggests that by using music as an interactive element displayed on e-commerce, consumers tend to evaluate better the purchase experience while increasing their cognitive involvement with the purchase, and consequently, increasing their purchase intention [24]. Therefore, some brands use sounds as a strategy to engage consumers. An example of this is the case of the Lays brand, which consistently uses sounds in their digital interaction with consumers to encourage potato chips' consumption by making consumers listen to crunchy sounds while purchasing their products [25].

Notably, previous research has suggested that emotions are also a critical component of a product's user experience [26], and where sounds can play a crucial role as they can activate emotional responses through basic concept associations [27]. The sounds of beverage manipulation, for example, have been found to be more pleasant than other product sounds [28]. Previous evidence has also shown the influence that packaging sounds can prompt on sensory expectations or actual taste perceptions [29-31]. Accordingly, we addressed the present study focusing on emotions and sensory expectations. Importantly, multisensory approaches in online retail experiences are becoming increasingly relevant as part of food and beverage marketing strategies as well. Hence, researchers may be encouraged to look for new and creative ways to implement effective cues across the senses to meet the growing online shopping demand [20,32].

To summarize, the main objective of this study was to find out how intrinsic product sounds nudge the purchase of a NAB in digital contexts. For this, we conducted two experiments, where each experiment tested one specific hypothesis. In the first experiment (H1), we assessed how different experiential beer packaging sounds would shape consumers' general emotions and sensory expectations when presented across different frequency and sound pressure ranges. In the second experiment $(\mathrm{H} 2)$, we analyzed how the sounds that prompted the most favorable results in the first experiment, when presented with the image of a NAB, would influence emotions and sensory expectations related to such NAB in a digital environment.

Hypothesis 1 (H1). Experiential beer packaging sounds will distinctively modulate emotional state (i.e., positive vs. negative), as well as sensory expectations (i.e., sweetness, bitterness, alcohol strength, refreshing).

Hypothesis 2 (H2). The experiential beer packaging sound(s) that evoked more positive scores in $H 1$ will positively modulate the scores associated with a digital image of a NAB. 


\section{Experiment 1}

\subsection{Materials and Methods}

\subsubsection{Participants}

One hundred and ninety-two (192) participants were directly invited to join Experiment 1 (gender-balanced sample). Responders were all over 18 years old (average age $=21.32$ years; $\mathrm{SD}=4.70)$ and were primarily undergraduate students from Universidad de Los Andes (Colombia). The sample size was calculated using a power analysis based on Friedman's simplified determinations of statistical power [33]. Considering a $95 \%$ confidence level ( $\alpha=0.05$ ), an effect size of 0.2 , and power of $80 \%$, the estimated sample size needed was set at approximately 191 individuals.

\subsubsection{Materials and Stimuli}

Pouring and opening sounds of a beer can and bottle were used as stimuli in Experiment 1 . Two previous studies were used as support for the choice of such experiential beer packaging sounds. On the one hand, Spence et al. [16] suggested that the typical beverage product experiential sounds conveying important information are opening and pouring sounds. On the other hand, according to Almiron et al. [17], opening sounds may play a unique role in the beer experience since they are the first noticeable sounds, setting product-related expectations that may anchor the subsequent tasting experience. In fact, the sounds used in Experiment 1 were taken from Almiron et al.'s study [17]. Each of these experiential beer packaging sounds (opening and pouring) had four different versions, concerning sound pressure level (minus $15 \mathrm{~dB}$ for the softer sounds) and frequency ranges (minus six semitones, for the lower frequency sounds; see Figure 1). Hence, in total, sixteen auditory stimuli were used in Experiment 1 . The stimuli can be accessed at https:/ / osf.io/ve3ap/ (accessed on 19 August 2021).

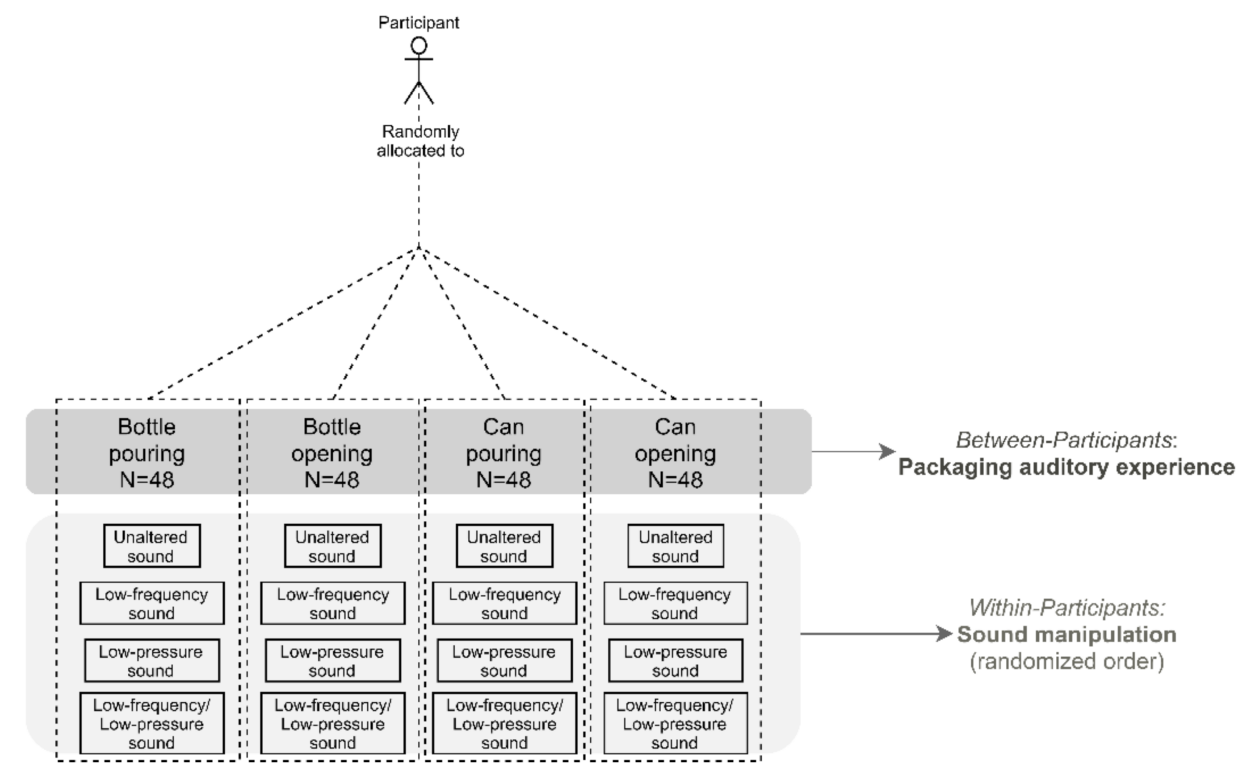

Figure 1. Design of Experiment 1, including the between- (packaging auditory experience) and within (sound manipulation)-participants conditions.

\subsubsection{Experimental Design}

As shown in Figure 1, Experiment 1 was based on a mixed-model experimental design. Here, four between-participants conditions were implemented. These conditions included a sound representing a typical beer packaging auditory experience (bottle pouring, bottle opening, can pouring, and can opening). For each between-participants condition, each participant was exposed to four versions of the same sound manipulated 
in terms of frequency and sound pressure (unaltered, low-frequency, low-pressure, and low-frequency/low-pressure sound).

\subsubsection{Procedure}

Experiment 1's survey was administrated on Qualtrics (https:/ / www.qualtrics.com, accessed on 19 August 2021), and designed to last for approximately $10 \mathrm{~min}$. Participants that agreed to join the study, providing their informed consent, were instructed to use headphones at all times and were randomly allocated to one of the four existing betweenparticipants conditions. Each participant had to pass through an audio calibration process prior to the beginning of the main experiment. This calibration involved listening to, and locating, the balance of a stereo sound of a bird chipping, while setting the hearing volume at a comfortable level. This calibration process also worked as a validation step to double-check if participants were using the headphones while answering the questionnaire.

During the main experiment, the participants listened to each of the four withinparticipants experimental sounds presented in random order. Participants were told they would hear a sound of a beer being opened (or poured) and were instructed to play the sound. After listening to each sound as often as they wanted, they were asked to answer how they felt after listening to the sound, rating 16 emotional terms presented in random order. Afterward, the participants also had to rate to what extent each sound was associated with four sensory parameters related to a beer experience (see Measures Section (Section 2.1.5) below for a more detailed explanation of the dependent variables).

Finally, the participants were asked about their demographic profile while also passing through additional validation steps to double-check if they were paying full attention during the experiment. This study was approved by the Universidad de los Andes ethics committee under Act 1357 of 2021.

\subsubsection{Measures}

In this study, we assessed two main dimensions of dependent variables: emotional and sensory ones. Concerning emotional scores, 16 terms were adapted from Silva et al. [11], which reported a list of emotions consistently associated with beer experiences. These 16 emotions were further subdivided into eleven positive (amused, calmed, comforted, curious, energetic, excited, friendly, good, joyful, pleased, responsible), one neutral (rational), and four negative (disappointed, grumpy, restless, sad) ones. Each emotion was evaluated by the participants based on the following instruction: "After hearing this sound, think about how it made you feel, and complete the following sentence: 'I FEEL ___.' (e.g., I FEEL AMUSED)". Concerning the sensory scores, participants were asked to indicate how refreshing, sweet, bitter, and strong (as in beer alcohol percentage) they expected the beer associated with the sound they were listening to be. All answers were based on a 7-point scale, with 1 being "not at all" and 7 "very much".

\subsubsection{Data Analysis}

All data analyses were performed using IBM SPSS 26.0. Main effects were tested using the repeated-measures general linear model with sound manipulation (unaltered, low-frequency, low-pressure, and low-frequency and pressure) as a within-participants factor, and the packaging auditory experience (bottle pouring, bottle opening, can pouring, and can opening) as a between-participants factor. As for the dependent variables, two independent models were executed to observe the emotion scores, and the sensory expectations, separately. Pairwise comparisons were Bonferroni-corrected. Since gender was balanced and age variance was relatively low, they were not included as covariates during data analyses. 


\subsection{Results}

\subsubsection{Emotion Scores}

The results of the multivariate tests (Pillai's Trace) revealed that there was a main effect of beer packaging auditory experience at the between-participants level $(\mathrm{F}(48,525)=2.05$; $\left.p<0.01 ; \eta^{2} \mathrm{p}=0.16\right)$, and of manipulation at the within-participants level $(\mathrm{F}(48,141)=2.67$; $\left.p<0.01 ; \eta^{2} \mathrm{p}=0.48\right)$. No interaction effects were found for packaging auditory experience and sound manipulation $\left(\mathrm{F}(144,429)=0.90 ; p=0.763 ; \eta^{2} \mathrm{p}=0.23\right)$.

Table 1 shows the univariate tests at the within-participants level (Greenhouse-Geissercorrected). There was a main effect of sound manipulation on specific positive (amused $(p<0.01)$, comforted $(p<0.01)$, curious $(p<0.01)$, energetic $(p<0.01)$, excited $(p<0.01)$, friendly $(p<0.01)$, good $(p<0.01)$, joyful $(p<0.01)$, pleased $(p<0.01)$, and responsible $(p<0.05))$ and negative (disappointed $(p<0.01)$, grumpy $(p<0.05))$ emotion scores. No effects of sound manipulation were found for calmed, restless, and rational scores.

Table 1. Summary of the results of univariate tests (Greenhouse-Geisser-corrected) of Experiment 1 at the within-participants level (sound manipulation condition) on each emotion score.

\begin{tabular}{ccccccc}
\hline Source & Calmed & $\begin{array}{c}\text { Degrees of } \\
\text { Freedom }\end{array}$ & $\begin{array}{c}\text { Mean } \\
\text { Square }\end{array}$ & F & $\begin{array}{c}p \text {-Value } \\
\text { Partial Eta } \\
\text { Squared }\end{array}$ \\
\hline & Amused & 2.71 & 34.89 & 20.11 & $<0.01$ & 0.10 \\
& Comforted & 2.97 & 2.43 & 1.41 & 0.24 & 0.01 \\
& Curious & 2.84 & 16.40 & 8.65 & $<0.01$ & 0.04 \\
& Disappointed & 2.79 & 12.12 & 6.61 & $<0.01$ & 0.03 \\
Sound ma- & Energetic & 2.76 & 16.40 & 8.69 & $<0.01$ & 0.04 \\
nipulation & Excited & 2.68 & 23.24 & 25.66 & $<0.01$ & 0.12 \\
& Friendly & 2.70 & 17.08 & 11.23 & $<0.01$ & 0.06 \\
& Good & 2.76 & 8.84 & 5.83 & $<0.01$ & 0.06 \\
& Grumpy & 2.89 & 3.97 & 2.97 & 0.03 & 0.03 \\
& Joyful & 2.73 & 21.78 & 13.34 & $<0.01$ & 0.02 \\
& Pleased & 2.82 & 25.54 & 12.55 & $<0.01$ & 0.07 \\
& Restless & 2.95 & 0.60 & 0.38 & 0.76 & 0.06 \\
& Sad & 2.88 & 9.41 & 9.51 & $<0.01$ & 0.05 \\
& Rational & 2.95 & 1.24 & 1.03 & 0.38 & 0.01 \\
& Responsible & 2.92 & 3.11 & 3.00 & 0.03 & 0.02
\end{tabular}

Table 2 shows the univariate tests at the between-participants level. There was a main effect of packaging auditory experience on specific positive (amused $(p<0.05)$, calmed $(p<0.01)$, comforted $(p<0.01)$, curious $(p<0.05)$, excited $(p<0.01)$, friendly $(p<0.01)$, good $(p<0.01)$, joyful $(p<0.05)$, and pleased $(p<0.01))$, neutral (rational $(p<0.05))$, as well as negative (disappointed $(p<0.01)$, grumpy $(p<0.01)$, restless $(p<0.01)$, and sad $(p<0.05))$ emotion scores. No effects of packaging auditory experience were found for energetic and responsible scores.

The overall evidence obtained through these pairwise comparisons points to the bottle pouring sound as the one evoking the highest scores across the positive emotions dimension, followed by the can pouring and bottle opening sounds. Note that the sound of a can opening elicited the lowest scores on most positive emotion scores (see Table A1 in Appendix A). When it comes to the sound manipulation condition, the unaltered sound generally elicited the highest scores on the positive emotions, followed by its low-frequency version. Low-frequency/low-pressure and low-pressure sound versions evoked the lowest scores on positive emotion scores (see Table A2 in Appendix A). Concerning the negative emotions dimension, the bottle pouring sound elicited the lowest scores, followed by the bottle opening sound. The sounds of can opening and can pouring evoked the overall highest scores on the negative emotions (see Table A1 in Appendix A). When it comes to the sound manipulation condition, the unaltered and low-pressure sound versions elicited the lowest scores on negative emotions, followed by the low-frequency version of the sound. 
The low-frequency/low-pressure sound version evoked the highest scores on negative emotions and the responsible emotion score (see Table A2 in Appendix A). Finally, it is noteworthy that rational scores were the only ones whose evidence was not conclusive.

Table 2. Summary of the results of the univariate tests of Experiment 1 at the between-participants level (packaging auditory experience condition) on each emotion score.

\begin{tabular}{ccccccc}
\hline Source & Mean & $\begin{array}{c}\text { Degrees of } \\
\text { Freedom }\end{array}$ & $\begin{array}{c}\text { Mean } \\
\text { Square }\end{array}$ & F & $p$-Value & $\begin{array}{c}\text { Partial Eta } \\
\text { Squared }\end{array}$ \\
\hline & Amused & 3.00 & 34.77 & 3.81 & 0.01 & 0.06 \\
& Calmed & 3.00 & 31.70 & 4.24 & 0.01 & 0.06 \\
& Comforted & 3.00 & 47.63 & 6.06 & $<0.01$ & 0.09 \\
& Curious & 3.00 & 25.01 & 2.74 & 0.04 & 0.04 \\
& Disappointed & 3.00 & 35.72 & 5.97 & $<0.01$ & 0.09 \\
Packaging & Energetic & 3.00 & 17.38 & 1.94 & 0.12 & 0.03 \\
auditory & Excited & 3.00 & 46.46 & 5.08 & $<0.01$ & 0.07 \\
experience & Friendly & 3.00 & 42.40 & 4.44 & $<0.01$ & 0.07 \\
& Good & 3.00 & 49.98 & 7.13 & $<0.01$ & 0.10 \\
& Grumpy & 3.00 & 20.52 & 4.31 & 0.01 & 0.06 \\
& Joyful & 3.00 & 29.40 & 3.29 & 0.02 & 0.05 \\
& Pleased & 3.00 & 62.96 & 7.93 & $<0.01$ & 0.11 \\
& Restless & 3.00 & 27.44 & 4.54 & $<0.01$ & 0.07 \\
& Sad & 3.00 & 10.55 & 2.82 & 0.04 & 0.04 \\
& Rational & 3.00 & 23.38 & 3.15 & 0.03 & 0.05 \\
& Responsible & 3.00 & 10.23 & 1.31 & 0.27 & 0.02 \\
\hline
\end{tabular}

\subsubsection{Sensory Expectations}

The results of the multivariate tests (Pillai's Trace) revealed that there was a main effect of packaging auditory experience at the between-participants level $(\mathrm{F}(12,561)=3.44 ; p<0.01$; $\left.\eta^{2} \mathrm{p}=0.07\right)$, and of sound manipulation at the within-participants level $(\mathrm{F}(12,177)=6.42$; $p<0.01 ; \eta^{2} \mathrm{p}=0.30$ ). No interaction effects were found for packaging auditory experience and sound manipulation $\left(\mathrm{F}(36,537)=0.98 ; p=0.500 ; \eta^{2} \mathrm{p}=0.06\right)$.

Table 3 shows the results of the univariate tests at the within-participants level (Greenhouse-Geisser-corrected). Here, the main effect of sound manipulation on every sensory expectation was detected (alcohol level $(p<0.01)$, refreshing $(p<0.01)$, sweetness $(p<0.01)$, and bitterness $(p<0.01))$.

Table 3. Summary of the results of the univariate tests (Greenhouse-Geisser-corrected) of Experiment 1 at the within-participants level (sound manipulation condition) on each sensory score.

\begin{tabular}{lcccccc}
\hline Source & & $\begin{array}{c}\text { Degrees of } \\
\text { Freedom }\end{array}$ & $\begin{array}{c}\text { Mean } \\
\text { Square }\end{array}$ & F & $p$-Value & $\begin{array}{c}\text { Partial Eta } \\
\text { Squared }\end{array}$ \\
\hline \multirow{3}{*}{ Sound ma- } & Alcohol & 2.64 & 17.60 & 12.04 & $<0.01$ & 0.06 \\
nipulation & Refreshing & 2.60 & 57.69 & 23.97 & $<0.01$ & 0.11 \\
& Sweetness & 2.94 & 6.96 & 3.98 & 0.01 & 0.02 \\
& Bitterness & 2.98 & 7.89 & 3.88 & 0.01 & 0.02 \\
\hline
\end{tabular}

Table 4 shows the results of the univariate tests at the between-participants level, where the main effect of packaging auditory experience sounds was found only for the refreshing scores $(p<0.01)$. No effects of packaging auditory experiences were found for the alcohol level, sweetness, and bitterness sensory scores.

The corresponding pairwise comparisons showed that the bottle pouring sound evoked the highest refreshing scores compared to other packaging sounds (see Tables A3 and A4 in Appendix A). Concerning the sound manipulation condition, the unaltered and lowfrequency versions of the sounds boosted more refreshing and alcohol strength scores when compared to the low-pressure and low-frequency/low-pressure versions. The sweetness scores were higher with the low-pressure version of the sound than with the low-frequency 
one. Conversely, the bitterness scores were higher with the low-frequency version of the sound than the low-pressure one. The unaltered and the low-frequency/low-pressure versions did not show significant differences concerning sweetness and bitterness scores.

Table 4. Summary of the results of the univariate tests of Experiment 1 at the between-participants level (packaging auditory experience condition) on each sensory score.

\begin{tabular}{ccccccc}
\hline Source & & $\begin{array}{c}\text { Degrees of } \\
\text { Freedom }\end{array}$ & $\begin{array}{c}\text { Mean } \\
\text { Square }\end{array}$ & F & $\boldsymbol{p}$-Value & $\begin{array}{c}\text { Partial Eta } \\
\text { Squared }\end{array}$ \\
\hline \multirow{2}{*}{ Packaging } & Alcohol & 3.00 & 9.14 & 0.87 & 0.46 & 0.01 \\
auditory & Refreshing & 3.00 & 70.78 & 9.64 & $<0.01$ & 0.13 \\
experience & Sweetness & 3.00 & 15.65 & 2.29 & 0.08 & 0.04 \\
& Bitterness & 3.00 & 13.91 & 1.58 & 0.20 & 0.02 \\
\hline
\end{tabular}

\section{Experiment 2}

\subsection{Participants}

Four hundred participants joined Experiment 2 (female $=38 \%$ ). Participants were all over 18 years old (mean age: 25.4 years; $\mathrm{SD}=8.4$ ), and $61 \%$ reported drinking beer at least once a month, while $80 \%$ reported rarely drinking NAB (i.e., less than once a month). All participants were recruited via Prolific, which is a British database company specialized in setting panels for online experiments (https://www.prolific.co/, accessed on 19 August 2021). Each participant was remunerated with approximately US $\$ 0.95$ for their participation in this study. Considering a 95\% confidence level $(\alpha=0.05)$, an effect size of 0.15 , and power of $80 \%$, the estimated sample size needed was set at approximately 343 individuals [33].

\subsection{Materials and Stimuli}

\subsubsection{Auditory Stimuli}

The beer bottle pouring sound showed general evidence of triggering the most positive effects in Experiment 1 (see results of Experiment 1). First, the unaltered version of the beer bottle pouring sound triggered the highest scores on most positive emotions. Secondly, the low-frequency version of this beer bottle pouring sound prompted the highest scores on alcohol strength and bitterness expectations. Third, the low-pressure version of the same beer bottle pouring sound triggered the highest scores on sweetness expectation. Hence, these three sounds were chosen as auditory stimuli for Experiment 2 (see Figure 2).

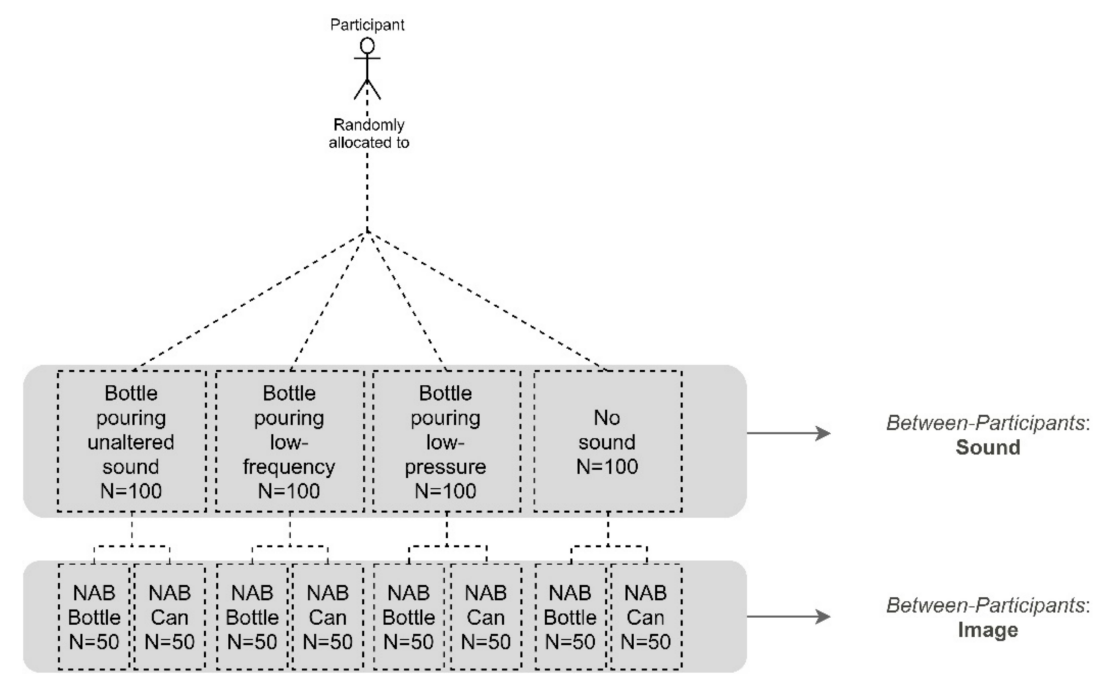

Figure 2. Design of Experiment 2 including the two types of stimuli (sound and image) employed simultaneously in the between-participants condition. 


\subsubsection{Visual Stimuli}

Each of the chosen three experimental sounds were presented with a customized NAB brand-free image, representing a digital NAB experience of beer poured into glassware (see Figure 3 for both bottle and can versions of NAB used in Experiment 2). The labels had a blue background since NAB versions of most well-known beer brands usually include this color as part of their labeling. Importantly, blue background labels usually represent lighter and healthier product versions [34-36]. This experimental label also contained information that the poured product was a $0.0 \%$ alcohol type of beer (NAB). Both images were produced using Adobe Photoshop CS6 software and relied on baseline images under creative commons licensing.

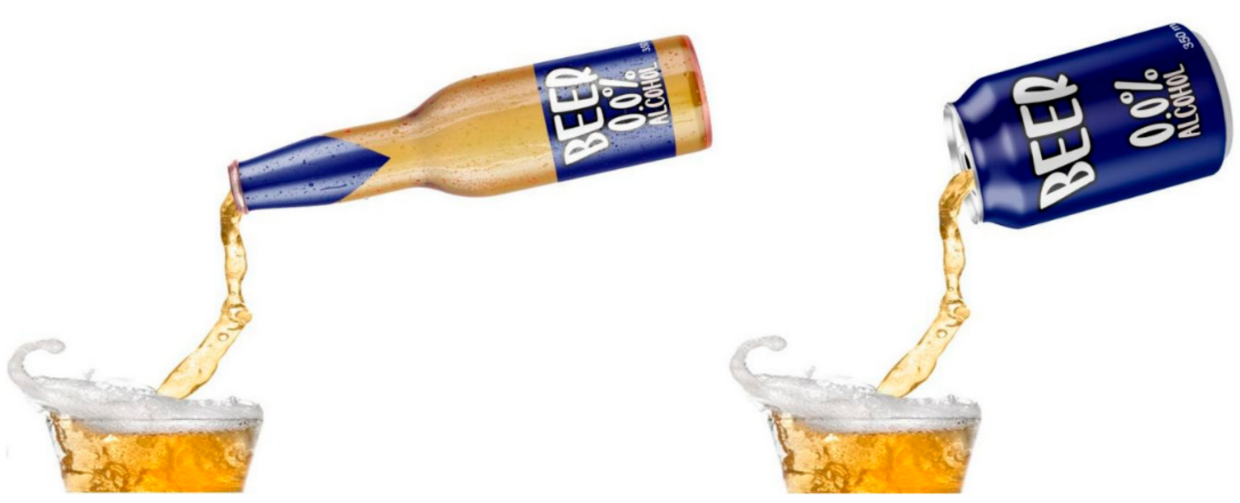

Figure 3. Visual stimuli used in Experiment 2. Left: NAB bottle pouring. Right: NAB can pouring.

\subsection{Methods}

\subsubsection{Design}

In Experiment 2, each participant was randomly exposed to one out of the three auditory conditions selected from Experiment 1, plus a control no-sound condition (unaltered version of a beer bottle pouring, low-frequency version of beer bottle pouring, low-pressure version of a beer bottle pouring, or no sound at all). To simulate a NAB online shopping experience, each sound was presented along with one of the existing NAB images, depending on which condition the participant was randomly assigned to (see Figure 2 for an overview of this experimental design). In total, there were eight experimental between-participants conditions (combining the existing four auditory cues, and the two available images).

\subsubsection{Procedure}

Experiment 2 was delivered via Qualtrics (https://www.qualtrics.com, accessed on 19 August 2021), and designed to last for approximately $5 \mathrm{~min}$. The procedure of Experiment 2 was the same as in Experiment 1, with the main difference being that each participant had only one stimulus to evaluate (hence, no within-participants comparisons), and such stimulus was audiovisual (meaning image plus sound). Moreover, at the end of the survey of Experiment 2, the participants were asked about their beer and NAB consumption habits.

\subsubsection{Data Analysis}

Statistical analyses were performed using IBM SPSS 26.0. Main effects and interactions were assessed using two independent multivariate ANOVA general linear models. Each independent ANOVA calculated the emotion scores and sensory expectations, independently, with two fixed factors (image and sound). Age, gender, and beer/NAB consumption habits were included as covariates. Pairwise comparisons were Bonferroni-corrected. To assess how the covariates affected the emotion scores, correlations were obtained via Pearson's method. 


\subsection{Results}

\subsubsection{Emotion Scores}

Table 5 shows the results of the multivariate tests (Pillai's Trace). Here, a main effect of sound $(p<0.01)$ was detected. A main effect of NAB consumption habit $(p<0.05)$ and age $(p<0.01)$ on results was also detected. No main effect was found for the image $(p=0.073)$ or its interaction with sound $(p=0.580)$. There was no effect of gender $(p=0.065)$ and beer consumption habit $(p=0.114)$ on results.

Table 5. Summary of the results of the Pillai's Trace multivariate tests for the emotion scores in Experiment 2.

\begin{tabular}{|c|c|c|c|c|c|c|}
\hline Effect & Value & $\mathbf{F}$ & $\begin{array}{c}\text { Hypothesis Degrees } \\
\text { of Freedom }\end{array}$ & $\begin{array}{l}\text { Error Degrees of } \\
\text { Freedom }\end{array}$ & $p$-Value & $\begin{array}{l}\text { Partial Eta } \\
\text { Squared }\end{array}$ \\
\hline Beer consumption habit & 0.06 & 1.61 & 16.00 & 373.00 & 0.06 & 0.06 \\
\hline NAB consumption habit & 0.07 & 1.82 & 16.00 & 373.00 & 0.03 & 0.07 \\
\hline Age & 0.12 & 3.16 & 16.00 & 373.00 & $<0.01$ & 0.12 \\
\hline Gender & 0.06 & 1.45 & 16.00 & 373.00 & 0.11 & 0.06 \\
\hline Image & 0.06 & 1.57 & 16.00 & 373.00 & 0.07 & 0.06 \\
\hline Sound & 0.28 & 2.43 & 48.00 & 1125.00 & $<0.01$ & 0.09 \\
\hline Image $^{*}$ Sound ${ }^{1}$ & 0.12 & 0.95 & 48.00 & 1125.00 & 0.58 & 0.04 \\
\hline
\end{tabular}

The univariate tests revealed a main effect of sound on specific positive (calmed $(p<0.01)$, comforted $(p<0.01)$, excited $(p<0.01)$, friendly $(p<0.05)$, good $(p<0.01)$, joyful $(p<0.01)$, pleased $(p<0.01)$, and responsible $(p<0.01))$ and negative (sad $(p<0.01)$, grumpy $(p<0.01)$, and disappointed $(p<0.01))$ emotion scores. These results also showed a main effect of the NAB consumption habit covariate on specific positive (comforted $(p<0.05)$, energetic $(p<0.05)$, excited $(p<0.01)$, good $(p<0.05)$, responsible $(p<0.05))$ and neutral (rational $(p<0.01)$ ) emotion scores (see Table 6$)$. Moreover, the age covariate showed a main effect on comforted $(p<0.05)$, energetic $(p<0.05)$, and grumpy $(p<0.01)$ emotion scores. Amused, curious, and restless emotion scores did not prompt effects.

Table 6. Summary of the results of the univariate tests at the between-participants level on each emotion score in Experiment 2.

\begin{tabular}{|c|c|c|c|c|c|c|}
\hline Source & & $\begin{array}{l}\text { Degrees of } \\
\text { Freedom }\end{array}$ & $\begin{array}{l}\text { Mean } \\
\text { Square }\end{array}$ & F & $p$-Value & $\begin{array}{c}\text { Partial Eta } \\
\text { Squared }\end{array}$ \\
\hline \multirow{16}{*}{$\begin{array}{c}\text { NAB } \\
\text { consumption } \\
\text { habit }\end{array}$} & Amused & 1.00 & 9.12 & 3.10 & 0.08 & 0.01 \\
\hline & Calmed & 1.00 & 3.42 & 1.32 & 0.25 & 0.00 \\
\hline & Comforted & 1.00 & 16.19 & 6.53 & 0.01 & 0.02 \\
\hline & Curious & 1.00 & 0.60 & 0.21 & 0.65 & 0.00 \\
\hline & Disappointed & 1.00 & 0.57 & 0.35 & 0.55 & 0.00 \\
\hline & Energetic & 1.00 & 9.37 & 3.96 & 0.05 & 0.01 \\
\hline & Excited & 1.00 & 32.32 & 12.18 & $<0.01$ & 0.03 \\
\hline & Friendly & 1.00 & 0.14 & 0.06 & 0.80 & 0.00 \\
\hline & Good & 1.00 & 11.19 & 5.70 & 0.02 & 0.01 \\
\hline & Grumpy & 1.00 & 0.54 & 0.31 & 0.58 & 0.00 \\
\hline & Joyful & 1.00 & 5.09 & 2.11 & 0.15 & 0.01 \\
\hline & Pleased & 1.00 & 6.46 & 3.06 & 0.08 & 0.01 \\
\hline & Restless & 1.00 & 0.07 & 0.03 & 0.86 & 0.00 \\
\hline & Sad & 1.00 & 0.09 & 0.06 & 0.81 & 0.00 \\
\hline & Rational & 1.00 & 26.11 & 11.04 & $<0.01$ & 0.03 \\
\hline & Responsible & 1.00 & 12.94 & 4.72 & 0.03 & 0.01 \\
\hline
\end{tabular}


Table 6. Cont.

\begin{tabular}{|c|c|c|c|c|c|c|}
\hline Source & & $\begin{array}{l}\text { Degrees of } \\
\text { Freedom }\end{array}$ & $\begin{array}{l}\text { Mean } \\
\text { Square }\end{array}$ & $\mathbf{F}$ & $p$-Value & $\begin{array}{l}\text { Partial Eta } \\
\text { Squared }\end{array}$ \\
\hline \multirow{16}{*}{ Age } & Amused & 1.00 & 0.32 & 0.11 & 0.74 & 0.00 \\
\hline & Calmed & 1.00 & 3.67 & 1.41 & 0.24 & 0.00 \\
\hline & Comforted & 1.00 & 11.60 & 4.68 & 0.03 & 0.01 \\
\hline & Curious & 1.00 & 8.60 & 2.96 & 0.09 & 0.01 \\
\hline & Disappointed & 1.00 & 0.96 & 0.59 & 0.44 & 0.00 \\
\hline & Energetic & 1.00 & 11.99 & 5.08 & 0.02 & 0.01 \\
\hline & Excited & 1.00 & 0.11 & 0.04 & 0.84 & 0.00 \\
\hline & Friendly & 1.00 & 0.36 & 0.16 & 0.69 & 0.00 \\
\hline & Good & 1.00 & 0.52 & 0.26 & 0.61 & 0.00 \\
\hline & Grumpy & 1.00 & 14.40 & 8.27 & $<0.01$ & 0.02 \\
\hline & Joyful & 1.00 & 5.07 & 2.10 & 0.15 & 0.01 \\
\hline & Pleased & 1.00 & 0.14 & 0.07 & 0.80 & 0.00 \\
\hline & Restless & 1.00 & 4.31 & 1.97 & 0.16 & 0.01 \\
\hline & Sad & 1.00 & 1.02 & 0.66 & 0.42 & 0.00 \\
\hline & Rational & 1.00 & 2.70 & 1.14 & 0.29 & 0.00 \\
\hline & Responsible & 1.00 & 7.93 & 2.89 & 0.09 & 0.01 \\
\hline \multirow{16}{*}{ Sound } & Amused & 3.00 & 4.05 & 1.38 & 0.25 & 0.01 \\
\hline & Calmed & 3.00 & 36.32 & 14.01 & $<0.01$ & 0.10 \\
\hline & Comforted & 3.00 & 25.63 & 10.34 & $<0.01$ & 0.07 \\
\hline & Curious & 3.00 & 0.34 & 0.12 & 0.95 & 0.00 \\
\hline & Disappointed & 3.00 & 12.94 & 8.03 & $<0.01$ & 0.06 \\
\hline & Energetic & 3.00 & 3.85 & 1.63 & 0.18 & 0.01 \\
\hline & Excited & 3.00 & 13.99 & 5.27 & $<0.01$ & 0.04 \\
\hline & Friendly & 3.00 & 6.52 & 2.91 & 0.03 & 0.02 \\
\hline & Good & 3.00 & 11.71 & 5.97 & $<0.01$ & 0.04 \\
\hline & Grumpy & 3.00 & 11.07 & 6.36 & $<0.01$ & 0.05 \\
\hline & Joyful & 3.00 & 15.59 & 6.47 & $<0.01$ & 0.05 \\
\hline & Pleased & 3.00 & 24.03 & 11.39 & $<0.01$ & 0.08 \\
\hline & Restless & 3.00 & 4.15 & 1.89 & 0.13 & 0.01 \\
\hline & Sad & 3.00 & 6.44 & 4.20 & 0.01 & 0.03 \\
\hline & Rational & 3.00 & 2.93 & 1.24 & 0.30 & 0.01 \\
\hline & Responsible & 3.00 & 14.56 & 5.31 & $<0.01$ & 0.04 \\
\hline
\end{tabular}

Figure 4 depicts a visual representation of the participants' scores in Experiment 2, concerning the emotion scores, and under each sound condition. Here, it is possible to visually appreciate how the emotion scores of the participants under the no-sound condition stand in sharp contrast to the participants who listened to a sound while rating.

The corresponding pairwise comparisons showed overall evidence that most positive emotion scores were higher under any bottle pouring sound conditions when compared to the no-sound condition. The no-sound condition, in turn, elicited the highest scores concerning negative emotions, followed by low-frequency and low-pressure sound versions. The unaltered version of the sound elicited the lowest scores on the negative emotions. Responsible emotion scores were also higher under the no-sound condition (see Table A5 in Appendix A). Pearson correlation analysis was conducted for age and NAB consumption habit covariates on the emotion scores that showed significant main effects (Table 6). The results of these correlations suggest that the more NAB consumption frequency, the higher scores on positive and neutral emotions (amused $(r=0.11)$, comforted $(r=0.17)$, energetic $(r=0.14)$, excited $(r=0.23)$, good $(r=0.17)$, rational $(r=0.19)$, and responsible $(r=0.11))$. There were no conclusive results concerning the effect of age on emotion scores. 


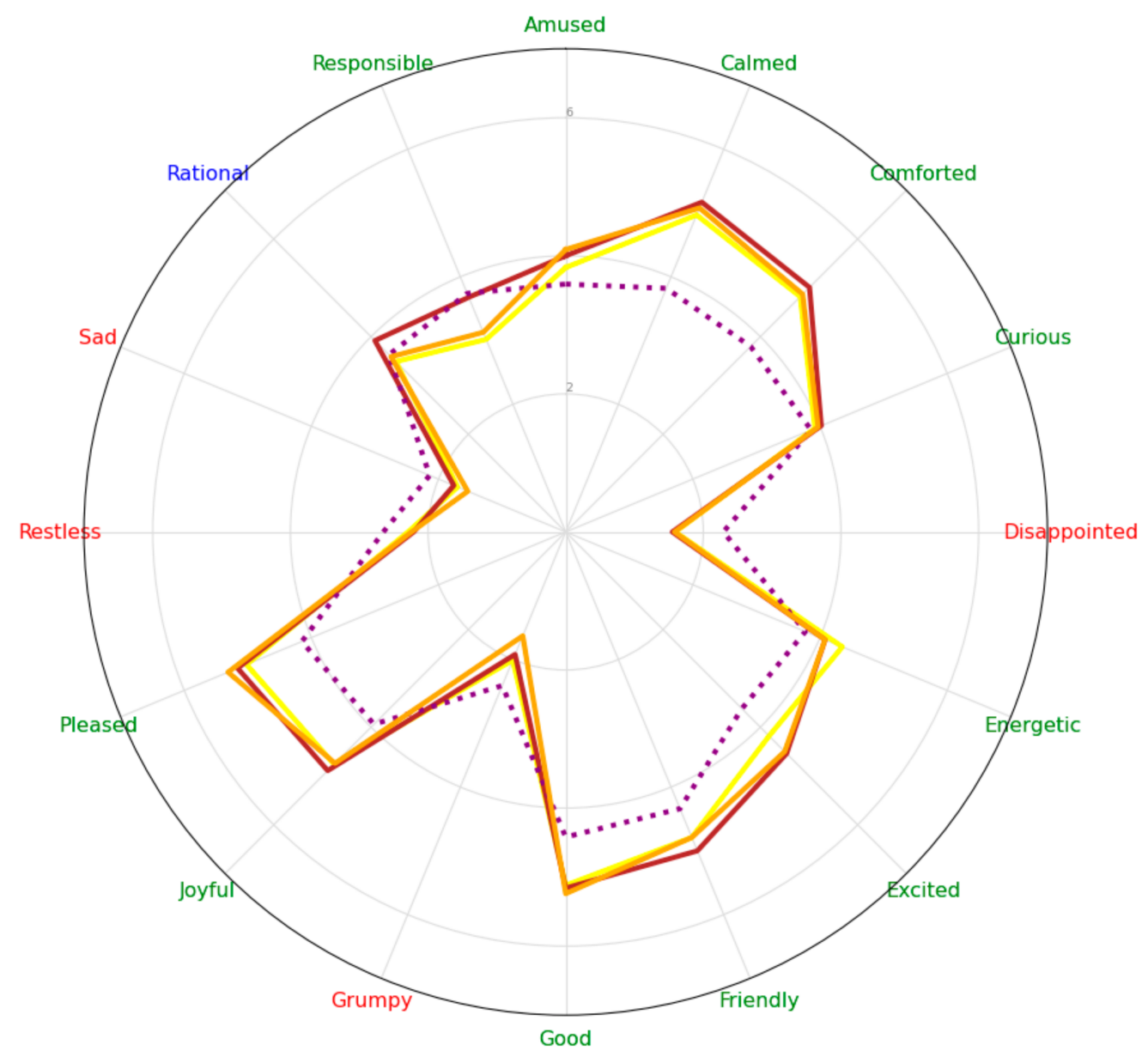

Figure 4. Radar chart with the mean averages of auditory conditions for every emotion score in Experiment 2. The purple/dotted-line represents the no-sound condition. The brown line, the lowpressure one. The yellow line, the low-frequency sound condition. The orange line, the unaltered sound condition.

\subsubsection{Sensory Expectations}

Table 7 shows the results of the multivariate tests for the sensory expectation scores (Pillai's Trace). Here, there was a main effect of sound $(p<0.01)$ and NAB consumption habit $(p<0.01)$ on results. No effects were found for the image $(p=0.654)$ or its interaction with sound $(p=0.594)$. There were also no effects of gender $(p=0.108)$, age $(p=0.239)$, or beer consumption habit $(p=0.402)$ on results.

Table 7. Summary of the results of the Pillai's Trace multivariate tests for the sensory scores in Experiment 2.

\begin{tabular}{ccccccc}
\hline Effect & Value & F & $\begin{array}{c}\text { Hypothesis Degrees } \\
\text { of Freedom }\end{array}$ & $\begin{array}{c}\text { Error Degrees of } \\
\text { Freedom }\end{array}$ & $\begin{array}{c}\boldsymbol{p} \text {-Value } \\
\text { Squared }\end{array}$ & $\begin{array}{c}\text { Partial Eta } \\
\text { Squared }\end{array}$ \\
\hline Beer consumption habit & 0.01 & 0.98 & 3.00 & 386.00 & 0.40 & 0.01 \\
NAB consumption habit & 0.05 & 6.82 & 3.00 & 386.00 & $<0.01$ & 0.05 \\
Age & 0.01 & 1.41 & 3.00 & 386.00 & 0.24 & 0.01 \\
Gender & 0.02 & 2.04 & 3.00 & 386.00 & 0.11 & 0.02 \\
Image & 0.00 & 0.54 & 3.00 & 386.00 & 0.65 & 0.00 \\
Sound $^{\text {Image * Sound }}{ }^{1}$ & 0.06 & 2.68 & 9.00 & 1164.00 & $<0.01$ & 0.02 \\
\hline
\end{tabular}

${ }^{*, 1}$ Interaction effect between image and sound factors. 
Table 8 shows the univariate test results. Here, there was a main effect of sound, and specifically on the refreshing expectations scores $(p<0.01)$. NAB consumption habit was found to affect the sweetness expectations scores $(p<0.01)$. No effects were found for the bitterness expectations.

Table 8. Summary of the results of the univariate tests at the between-participants level on each sensory expectation in Experiment 2.

\begin{tabular}{ccccccc}
\hline Source & Refreshing & $\begin{array}{c}\text { Degrees of } \\
\text { Freedom }\end{array}$ & $\begin{array}{c}\text { Mean } \\
\text { Square }\end{array}$ & F & $p$-Value & $\begin{array}{c}\text { Partial Eta } \\
\text { Squared }\end{array}$ \\
\hline NAB & 1.00 & 2.02 & 1.33 & 0.25 & 0.00 \\
consumption & Sweetness & 1.00 & 41.41 & 15.84 & $<0.01$ & 0.04 \\
habit & Bitterness & 1.00 & 6.33 & 2.13 & 0.15 & 0.01 \\
\hline \multirow{3}{*}{ Sound } & Refreshing & 3.00 & 9.28 & 6.10 & $<0.01$ & 0.05 \\
& Sweetness & 3.00 & 2.26 & 0.87 & 0.46 & 0.01 \\
& Bitterness & 3.00 & 5.52 & 1.86 & 0.14 & 0.01 \\
\hline
\end{tabular}

The unaltered bottle pouring sound and its low-pressure version elicited the highest refreshing expectations, followed by its low-frequency version. The no-sound condition evoked the lowest refreshing scores (see Table A6 in Appendix A). Pearson correlation analysis was conducted to assess the effect of NAB consumption habit on sweetness expectation scores, which prompted a significant main effect in the univariate tests (see Table 8). These correlations suggest that the more NAB consumption frequency, the higher scores on sweetness expectation $(r=0.20)$.

\section{Summary of All the Obtained Results}

The results obtained in Experiment 1 allowed us to select three particular experiential beer sounds that most positively influenced participants' emotions and sensory expectations (unaltered bottle pouring, low-frequency bottle pouring, and low-pressure bottle pouring sounds). In Experiment 2, we used those three selected sounds and assessed their role in a NAB simulated digital shopping experience. Principally, Experiment 2 results revealed that the unaltered bottle pouring sound triggered the most positive and the least negative emotions, as well as the highest refreshing expectations for the image of a NAB, compared to the other three auditory conditions (and regardless of whether the NAB was a can or a bottle). Moreover, in Experiment 2, regardless of sound or image condition, the participants that reported more often consuming NAB generally felt more positive and neutral (i.e., rational) in terms of emotions, while also generally expecting a sweeter NAB.

\section{Discussion}

This study generally focused on assessing how specific sounds associated with a beer packaging experience may influence consumer emotions and sensory expectations on a simulated digital shopping experience of a NAB. We were inspired by the possibility of using auditory cues to enable brands and organizations to more effectively nudge consumers to consider NAB as part of their evoked set during decision-making tasks related to beers and / or overall drink choices. Customizing packaging auditory experiences may be crucial due to the proven existing link between product sounds and emotions/expectations related to product consumption [37].

Overall, the results showed that particular emotions and sensory expectations were modulated depending on the auditory condition to which the participants were exposed. More specifically, by presenting an unaltered bottle pouring sound along with the image of a NAB being poured in a glass, we were able to counteract some of the negative emotions that are commonly associated with the experience of a NAB, while at the same time enhancing most of the positive emotion scores being assessed throughout the study. Note that the same bottle pouring sound significantly enhanced refreshing expectations for the $\mathrm{NAB}$ as well. 


\subsection{The Positive Effect That Experiential Beer Sounds Can Bring to the Experience of Consumers (H1)}

Experiment 1 was useful to identify which beer packaging sounds, customized in terms of acoustic parameters, might prompt significant and specific emotional effects and sensory expectations in the experience of consumers. We, therefore, showed that different experiential beer packaging sounds could modulate emotional state and sensory expectations in very particular ways (H1). The obtained results were somehow in line with previous research, where, for instance, the same unaltered bottle pouring sound used in this study was previously framed as more premium than other experiential beer packaging sounds [17]. In this previous study, the authors also suggested that the most premium sounds tend to be more semantically associated with positive adjectives, such as alive, good, nice, and happy. Hence, our results add value to the existing literature by providing insights on how a bottle pouring sound can enhance positive emotions and sensory expectations on beer product experiences. Such findings may be helpful while promoting specificities of the value proposition of any beer, including NAB.

Previous research has also shown that when consumers are induced into negative emotions (e.g., via music or movie clips), they tend to perceive a beer's flavor as more alcoholic, less sweet, and/or more bitter [38,39]. In Experiment 1, the auditory conditions that participants reported as the most negative were the low-frequency/low-pressure canopening/can-pouring ones. However, in such conditions, the alcohol content expectation scored by the participants was the lowest, and there were no other main effects observed in such auditory conditions on bitterness or sweetness expectations.

In another similar study, the freshness of carbonated beverages was more associated with high-pitched pouring sounds and small bubbles when compared to low-pitched pouring sounds and big bubbles [31]. However, in the sound manipulation condition of Experiment 1, the refreshing expectation was enhanced with the unaltered (vs. lowpressure) sound. Moreover, in Experiment 2, the refreshing expectations were significantly enhanced when participants listened to the unaltered (vs. low-frequency) sound, which is in line with Roque et al.'s study [31].

Hence, in the present study, we could conclude that the priming effect of a NAB image, as part of Experiment 2, improved the overall conception of this digital beer experience, while more accordingly shaping participants' emotional and sensory expectations than in Experiment 1.

\subsection{Using Experiential Beer Sounds to Nudge Consumers towards NAB Choices in Digital Shopping Environments (H2)}

In Experiment 2, we empirically showed that the usage of beer bottle pouring sounds could enhance positive emotions and refreshing expectations towards NAB in digital shopping environments. Here, we showed that the sound that evoked more positive emotions in Experiment 1 positively modulated the listener's emotions towards a NAB as well (H2). To the best of our knowledge, this is the first experiment where product sounds are being used to evoke positive impressions on NAB. Hence, we believe that these results may be important to those interested in the existing literature that focuses on the role of background sound and music on consumers' decision-making tasks associated with different dietary foods or beverages [40,41].

Notably, the unaltered beer bottle pouring sound enhanced the refreshing expectations of NAB, and such effects were obtained regardless of the NAB image shown to participants (i.e., beer or can). On the one hand, as explained before, the obtained results are in line with previous research, where it has been shown that high-pitched sounds representing small bubbling (vs. low-pitched sounds/big bubbling) tend to be more congruent with fresher sparkling beverages [31]. On the other hand, this finding may also indicate that consumers can disentangle the image from the sound while shopping in e-commerce, thus not framing the multisensory experience of the image of a can, when accompanied by a beer bottle pouring sound, as semantically incongruent. In other words, in this digital NAB experience, 
the bottle pouring sound may have acted as an standalone soundscape rather than as a part of the audiovisual experience associated with the product's image (see [27,42]).

On top of that, in Experiment 2, the participants that reported often consuming NAB generally acknowledged feeling more rational and responsible. Here, such participants also rated a NAB as generally sweeter. These findings seem logical since rational and responsible emotions are commonly associated with NAB consumption [10], and NAB is often considered sweeter than its alcoholic counterpart [43].

\subsection{General Implications}

It is well-known that emotions play an important role in purchase decision-making tasks [44,45]. As a matter of fact, in previous research, Silva et al. [11] found that a NAB was more liked when it was consumed "disguised" as an alcoholic beer, where participants felt more fulfilled under such a situation. The label of NAB, on its own, prompts negative (sad, disappointed, and grumpy) and weakens positive (comforted, exuberant, good, happy, joyful, and loving) emotions. In addition, consuming NAB evokes neutral and negative emotional responses, such as rational, conscious, and disappointed [10]. In this way, our results show that a customized experiential beer packaging sound can be employed to counteract such negativity commonly associated with NAB experiences.

Based on the obtained results, brands interested in more positively promoting NAB in a virtual shopping environment may feel encouraged to involve product packaging sounds as part of the customer's digital shopping experience. In particular, here, it has been shown that a beer bottle pouring sound can be used to elicit positive emotions during a NAB online shopping experience. In addition, a bottle pouring sound cannot only diminish negative emotions, but it may also be useful to boost NAB refreshing expectations. Thus, the present study broadens the scope of the current state-of-the-art by showing the effect that product sounds can have on emotions and sensory expectation variables in online retailing associated with NAB. Such variables could act as a support for crucial consumption ones as well, such as willingness to pay (see [20]).

As a matter of fact, healthy foods/beverage producers may consider promoting nutritional values (i.e., lower alcohol/calories/fat/sugar/salt content) via packaging sounds. When it comes to promoting healthy sparkling beverages, such as NAB, it has been suggested that people automatically tend to associate higher pitch and quieter sounds with a lower-calorie or reduced sugar product-although, as far as we are aware, the latter has not been empirically proven yet [15].

In brief, this study can motivate beer brands and organizations to consider including sound during packaging design strategies to enhance the multisensory shopping experience of their healthier product categories, such as NAB.

\subsection{Limitations and Future Work}

In online retail environments, products are not assessed individually but are usually compared across competing products within a specific category. Since our study only involved NAB, future similar work could examine the effects of similar sounds of a beer packaging experience when different types of beers are presented simultaneously to the participants. In this way, the setting would be more realistic, and emotions could play a different role. For example, future research could compare NAB paired with a pouring sound vs. regular beer with no sound to support the idea that sounds could not only increase the positive emotions related to $\mathrm{NAB}$ but could also encourage the preference of NAB over alcoholic beer. Additionally, variables such as liking, familiarity with the product, and willingness to pay may also be critical to measure along with emotions and sensory expectations in similar future assessments (see [20]).

Concerning methodology, we only manipulated the original experiential sounds towards lower frequency and sound pressure ranges. Future similar work could do the opposite by focusing on the higher frequency/pressure components of the sound stimuli. For instance, previous research found semantic associations between higher-pitched can 
opening sounds and specific comfort scores [18]. It may also be interesting to mix those experiential beer sounds with other sound cues that may be part of more realistic virtual retail experiences, such as background noise and/or music.

Author Contributions: Conceptualization, B.R., C.A., L.H.R. and F.R.-C.; methodology, B.R., C.A. and F.R.-C.; formal analysis, B.R. and C.A.; writing-review and editing, B.R., L.H.R. and F.R.-C. All authors have read and agreed to the published version of the manuscript.

Funding: The authors would like to thank the Vice Presidency of Research and Creation's publication Fund at Universidad de los Andes (Colombia), for its financial support.

Institutional Review Board Statement: The study was conducted according to the guidelines of the Declaration of Helsinki, and approved by the Ethics Committee of Universidad de los Andes (Act 1357 of 18 May 2021).

Informed Consent Statement: Informed consent was obtained from all subjects involved in the study.

Data Availability Statement: The original contributions presented in the study are included in the article. Further inquiries can be directed to the corresponding author.

Conflicts of Interest: The authors declare that the research was conducted in the absence of any commercial or financial relationships that could be construed as a potential conflict of interest.

\section{Appendix A}

Table A1. Summary of the results of the pairwise comparisons of Experiment 1 within-participants condition (sound manipulation) for emotion scores.

\begin{tabular}{|c|c|c|c|c|c|}
\hline Measure & & & $\begin{array}{c}\text { Mean } \\
\text { Difference }\end{array}$ & Std. Error & $p$-Value \\
\hline \multirow{12}{*}{ Amused } & \multirow{3}{*}{ Low-frequency } & Low-frequency/low-pressure & 0.73 & 0.14 & $<0.01$ \\
\hline & & Low-pressure & 0.46 & 0.14 & 0.01 \\
\hline & & Unaltered & -0.14 & 0.11 & 1.00 \\
\hline & \multirow{3}{*}{ Low-frequency/low-pressure } & Low-frequency & -0.73 & 0.14 & $<0.01$ \\
\hline & & Low-pressure & -0.27 & 0.11 & 0.10 \\
\hline & & Unaltered & -0.87 & 0.13 & $<0.01$ \\
\hline & \multirow{3}{*}{ Low-pressure } & Low-frequency & -0.46 & 0.14 & 0.01 \\
\hline & & Low-frequency/low-pressure & 0.27 & 0.11 & 0.10 \\
\hline & & Unaltered & -0.60 & 0.13 & $<0.01$ \\
\hline & \multirow{3}{*}{ Unaltered } & Low-frequency & 0.14 & 0.11 & 1.00 \\
\hline & & Low-frequency/low-pressure & 0.87 & 0.13 & $<0.01$ \\
\hline & & Low-pressure & 0.60 & 0.13 & $<0.01$ \\
\hline \multirow{12}{*}{ Calmed } & \multirow{3}{*}{ Low-frequency } & Low-frequency/low-pressure & 0.03 & 0.13 & 1.00 \\
\hline & & Low-pressure & -0.18 & 0.13 & 1.00 \\
\hline & & Unaltered & -0.18 & 0.13 & 1.00 \\
\hline & \multirow{3}{*}{ Low-frequency/low-pressure } & Low-frequency & -0.03 & 0.13 & 1.00 \\
\hline & & Low-pressure & -0.21 & 0.13 & 0.68 \\
\hline & & Unaltered & -0.21 & 0.13 & 0.69 \\
\hline & \multirow{3}{*}{ Low-pressure } & Low-frequency & 0.18 & 0.13 & 1.00 \\
\hline & & Low-frequency/low-pressure & 0.21 & 0.13 & 0.68 \\
\hline & & Unaltered & 0.00 & 0.14 & 1.00 \\
\hline & \multirow{3}{*}{ Unaltered } & Low-frequency & 0.18 & 0.13 & 1.00 \\
\hline & & Low-frequency/low-pressure & 0.21 & 0.13 & 0.69 \\
\hline & & Low-pressure & 0.00 & 0.14 & 1.00 \\
\hline
\end{tabular}


Table A1. Cont.

\begin{tabular}{|c|c|c|c|c|c|}
\hline Measure & & & $\begin{array}{c}\text { Mean } \\
\text { Difference }\end{array}$ & Std. Error & $p$-Value \\
\hline \multirow{12}{*}{ Comforted } & \multirow{3}{*}{ Low-frequency } & Low-frequency/low-pressure & 0.49 & 0.14 & $<0.01$ \\
\hline & & Low-pressure & 0.14 & 0.15 & 1.00 \\
\hline & & Unaltered & -0.19 & 0.14 & 1.00 \\
\hline & \multirow{3}{*}{ Low-frequency/low-pressure } & Low-frequency & -0.49 & 0.14 & $<0.01$ \\
\hline & & Low-pressure & -0.35 & 0.12 & 0.02 \\
\hline & & Unaltered & -0.68 & 0.14 & $<0.01$ \\
\hline & \multirow{3}{*}{ Low-pressure } & Low-frequency & -0.14 & 0.15 & 1.00 \\
\hline & & Low-frequency/low-pressure & 0.35 & 0.12 & 0.02 \\
\hline & & Unaltered & -0.32 & 0.14 & 0.14 \\
\hline & \multirow{3}{*}{ Unaltered } & Low-frequency & 0.19 & 0.14 & 1.00 \\
\hline & & Low-frequency/low-pressure & 0.68 & 0.14 & $<0.01$ \\
\hline & & Low-pressure & 0.32 & 0.14 & 0.14 \\
\hline \multirow{12}{*}{ Curious } & \multirow{3}{*}{ Low-frequency } & Low-frequency/low-pressure & 0.41 & 0.14 & 0.02 \\
\hline & & Low-pressure & 0.22 & 0.13 & 0.59 \\
\hline & & Unaltered & -0.15 & 0.14 & 1.00 \\
\hline & \multirow{3}{*}{ Low-frequency/low-pressure } & Low-frequency & -0.41 & 0.14 & 0.02 \\
\hline & & Low-pressure & -0.19 & 0.12 & 0.73 \\
\hline & & Unaltered & -0.56 & 0.15 & $<0.01$ \\
\hline & \multirow{3}{*}{ Low-pressure } & Low-frequency & -0.22 & 0.13 & 0.59 \\
\hline & & Low-frequency/low-pressure & 0.19 & 0.12 & 0.73 \\
\hline & & Unaltered & -0.37 & 0.13 & 0.02 \\
\hline & \multirow{3}{*}{ Unaltered } & Low-frequency & 0.15 & 0.14 & 1.00 \\
\hline & & Low-frequency/low-pressure & 0.56 & 0.15 & $<0.01$ \\
\hline & & Low-pressure & 0.37 & 0.13 & 0.02 \\
\hline \multirow{12}{*}{ Disappointed } & \multirow{3}{*}{ Low-frequency } & Low-frequency/low-pressure & -0.40 & 0.14 & 0.03 \\
\hline & & Low-pressure & -0.05 & 0.14 & 1.00 \\
\hline & & Unaltered & 0.29 & 0.12 & 0.12 \\
\hline & \multirow{3}{*}{ Low-frequency/low-pressure } & Low-frequency & 0.40 & 0.14 & 0.03 \\
\hline & & Low-pressure & 0.35 & 0.12 & 0.03 \\
\hline & & Unaltered & 0.69 & 0.15 & $<0.01$ \\
\hline & \multirow{3}{*}{ Low-pressure } & Low-frequency & 0.05 & 0.14 & 1.00 \\
\hline & & Low-frequency/low-pressure & -0.35 & 0.12 & 0.03 \\
\hline & & Unaltered & 0.34 & 0.13 & 0.08 \\
\hline & \multirow{3}{*}{ Unaltered } & Low-frequency & -0.29 & 0.12 & 0.12 \\
\hline & & Low-frequency/low-pressure & -0.69 & 0.15 & $<0.01$ \\
\hline & & Low-pressure & -0.34 & 0.13 & 0.08 \\
\hline \multirow{12}{*}{ Energetic } & \multirow{3}{*}{ Low-frequency } & Low-frequency/low-pressure & 0.70 & 0.13 & $<0.01$ \\
\hline & & Low-pressure & 0.38 & 0.13 & 0.03 \\
\hline & & Unaltered & -0.35 & 0.12 & 0.03 \\
\hline & \multirow{3}{*}{ Low-frequency/low-pressure } & Low-frequency & -0.70 & 0.13 & $<0.01$ \\
\hline & & Low-pressure & -0.32 & 0.10 & 0.02 \\
\hline & & Unaltered & -1.05 & 0.14 & $<0.01$ \\
\hline & \multirow{3}{*}{ Low-pressure } & Low-frequency & -0.38 & 0.13 & 0.03 \\
\hline & & Low-frequency/low-pressure & 0.32 & 0.10 & 0.02 \\
\hline & & Unaltered & -0.73 & 0.13 & $<0.01$ \\
\hline & \multirow{3}{*}{ Unaltered } & Low-frequency & 0.35 & 0.12 & 0.03 \\
\hline & & Low-frequency/low-pressure & 1.05 & 0.14 & $<0.01$ \\
\hline & & Low-pressure & 0.73 & 0.13 & $<0.01$ \\
\hline
\end{tabular}


Table A1. Cont.

\begin{tabular}{|c|c|c|c|c|c|}
\hline Measure & & & $\begin{array}{c}\text { Mean } \\
\text { Difference }\end{array}$ & Std. Error & $p$-Value \\
\hline \multirow{12}{*}{ Excited } & \multirow{3}{*}{ Low-frequency } & Low-frequency/low-pressure & 0.60 & 0.13 & $<0.01$ \\
\hline & & Low-pressure & 0.30 & 0.14 & 0.17 \\
\hline & & Unaltered & -0.11 & 0.12 & 1.00 \\
\hline & \multirow{3}{*}{ Low-frequency/low-pressure } & Low-frequency & -0.60 & 0.13 & $<0.01$ \\
\hline & & Low-pressure & -0.30 & 0.11 & 0.05 \\
\hline & & Unaltered & -0.71 & 0.15 & $<0.01$ \\
\hline & \multirow{3}{*}{ Low-pressure } & Low-frequency & -0.30 & 0.14 & 0.17 \\
\hline & & Low-frequency/low-pressure & 0.30 & 0.11 & 0.05 \\
\hline & & Unaltered & -0.42 & 0.14 & 0.02 \\
\hline & \multirow{3}{*}{ Unaltered } & Low-frequency & 0.11 & 0.12 & 1.00 \\
\hline & & Low-frequency/low-pressure & 0.71 & 0.15 & $<0.01$ \\
\hline & & Low-pressure & 0.42 & 0.14 & 0.02 \\
\hline \multirow{12}{*}{ Friendly } & \multirow{3}{*}{ Low-frequency } & Low-frequency/low-pressure & 0.45 & 0.13 & $<0.01$ \\
\hline & & Low-pressure & 0.06 & 0.12 & 1.00 \\
\hline & & Unaltered & -0.23 & 0.11 & 0.21 \\
\hline & \multirow{3}{*}{ Low-frequency/low-pressure } & Low-frequency & -0.45 & 0.13 & $<0.01$ \\
\hline & & Low-pressure & -0.39 & 0.10 & $<0.01$ \\
\hline & & Unaltered & -0.68 & 0.13 & $<0.01$ \\
\hline & \multirow{3}{*}{ Low-pressure } & Low-frequency & -0.06 & 0.12 & 1.00 \\
\hline & & Low-frequency/low-pressure & 0.39 & 0.10 & $<0.01$ \\
\hline & & Unaltered & -0.30 & 0.11 & 0.06 \\
\hline & \multirow{3}{*}{ Unaltered } & Low-frequency & 0.23 & 0.11 & 0.21 \\
\hline & & Low-frequency/low-pressure & 0.68 & 0.13 & $<0.01$ \\
\hline & & Low-pressure & 0.30 & 0.11 & 0.06 \\
\hline \multirow{12}{*}{ Good } & \multirow{3}{*}{ Low-frequency } & Low-frequency/low-pressure & 0.31 & 0.12 & 0.06 \\
\hline & & Low-pressure & 0.09 & 0.12 & 1.00 \\
\hline & & Unaltered & -0.18 & 0.11 & 0.60 \\
\hline & \multirow{3}{*}{ Low-frequency/low-pressure } & Low-frequency & -0.31 & 0.12 & 0.06 \\
\hline & & Low-pressure & -0.22 & 0.11 & 0.24 \\
\hline & & Unaltered & -0.50 & 0.13 & $<0.01$ \\
\hline & \multirow{3}{*}{ Low-pressure } & Low-frequency & -0.09 & 0.12 & 1.00 \\
\hline & & Low-frequency/low-pressure & 0.22 & 0.11 & 0.24 \\
\hline & & Unaltered & -0.28 & 0.13 & 0.21 \\
\hline & \multirow{3}{*}{ Unaltered } & Low-frequency & 0.18 & 0.11 & 0.60 \\
\hline & & Low-frequency/low-pressure & 0.50 & 0.13 & $<0.01$ \\
\hline & & Low-pressure & 0.28 & 0.13 & 0.21 \\
\hline \multirow{12}{*}{ Grumpy } & \multirow{3}{*}{ Low-frequency } & Low-frequency/low-pressure & -0.06 & 0.12 & 1.00 \\
\hline & & Low-pressure & 0.24 & 0.11 & 0.21 \\
\hline & & Unaltered & 0.18 & 0.12 & 0.78 \\
\hline & \multirow{3}{*}{ Low-frequency/low-pressure } & Low-frequency & 0.06 & 0.12 & 1.00 \\
\hline & & Low-pressure & 0.30 & 0.10 & 0.03 \\
\hline & & Unaltered & 0.23 & 0.12 & 0.32 \\
\hline & \multirow{3}{*}{ Low-pressure } & Low-frequency & -0.24 & 0.11 & 0.21 \\
\hline & & Low-frequency/low-pressure & -0.30 & 0.10 & 0.03 \\
\hline & & Unaltered & -0.06 & 0.12 & 1.00 \\
\hline & \multirow{3}{*}{ Unaltered } & Low-frequency & -0.18 & 0.12 & 0.78 \\
\hline & & Low-frequency/low-pressure & -0.23 & 0.12 & 0.32 \\
\hline & & Low-pressure & 0.06 & 0.12 & 1.00 \\
\hline
\end{tabular}


Table A1. Cont.

\begin{tabular}{|c|c|c|c|c|c|}
\hline Measure & & & $\begin{array}{c}\text { Mean } \\
\text { Difference }\end{array}$ & Std. Error & $p$-Value \\
\hline \multirow{12}{*}{ Joyful } & \multirow{3}{*}{ Low-frequency } & Low-frequency/low-pressure & 0.58 & 0.13 & $<0.01$ \\
\hline & & Low-pressure & 0.23 & 0.12 & 0.31 \\
\hline & & Unaltered & -0.16 & 0.11 & 0.86 \\
\hline & \multirow{3}{*}{ Low-frequency/low-pressure } & Low-frequency & -0.58 & 0.13 & $<0.01$ \\
\hline & & Low-pressure & -0.34 & 0.11 & 0.01 \\
\hline & & Unaltered & -0.74 & 0.14 & $<0.01$ \\
\hline & \multirow{3}{*}{ Low-pressure } & Low-frequency & -0.23 & 0.12 & 0.31 \\
\hline & & Low-frequency/low-pressure & 0.34 & 0.11 & 0.01 \\
\hline & & Unaltered & -0.40 & 0.13 & 0.02 \\
\hline & \multirow{3}{*}{ Unaltered } & Low-frequency & 0.16 & 0.11 & 0.86 \\
\hline & & Low-frequency/low-pressure & 0.74 & 0.14 & $<0.01$ \\
\hline & & Low-pressure & 0.40 & 0.13 & 0.02 \\
\hline \multirow{12}{*}{ Pleased } & \multirow{3}{*}{ Low-frequency } & Low-frequency/low-pressure & 0.62 & 0.14 & $<0.01$ \\
\hline & & Low-pressure & 0.31 & 0.14 & 0.18 \\
\hline & & Unaltered & -0.18 & 0.13 & 0.96 \\
\hline & \multirow{3}{*}{ Low-frequency/low-pressure } & Low-frequency & -0.62 & 0.14 & $<0.01$ \\
\hline & & Low-pressure & -0.31 & 0.13 & 0.11 \\
\hline & & Unaltered & -0.80 & 0.16 & $<0.01$ \\
\hline & \multirow{3}{*}{ Low-pressure } & Low-frequency & -0.31 & 0.14 & 0.18 \\
\hline & & Low-frequency/low-pressure & 0.31 & 0.13 & 0.11 \\
\hline & & Unaltered & -0.50 & 0.14 & $<0.01$ \\
\hline & \multirow{3}{*}{ Unaltered } & Low-frequency & 0.18 & 0.13 & 0.96 \\
\hline & & Low-frequency/low-pressure & 0.80 & 0.16 & $<0.01$ \\
\hline & & Low-pressure & 0.50 & 0.14 & $<0.01$ \\
\hline \multirow{12}{*}{ Restless } & \multirow{3}{*}{ Low-frequency } & Low-frequency/low-pressure & 0.11 & 0.13 & 1.00 \\
\hline & & Low-pressure & 0.12 & 0.12 & 1.00 \\
\hline & & Unaltered & 0.10 & 0.12 & 1.00 \\
\hline & \multirow{3}{*}{ Low-frequency/low-pressure } & Low-frequency & -0.11 & 0.13 & 1.00 \\
\hline & & Low-pressure & 0.01 & 0.13 & 1.00 \\
\hline & & Unaltered & -0.01 & 0.13 & 1.00 \\
\hline & \multirow{3}{*}{ Low-pressure } & Low-frequency & -0.12 & 0.12 & 1.00 \\
\hline & & Low-frequency/low-pressure & -0.01 & 0.13 & 1.00 \\
\hline & & Unaltered & -0.02 & 0.13 & 1.00 \\
\hline & \multirow{3}{*}{ Unaltered } & Low-frequency & -0.10 & 0.12 & 1.00 \\
\hline & & Low-frequency/low-pressure & 0.01 & 0.13 & 1.00 \\
\hline & & Low-pressure & 0.02 & 0.13 & 1.00 \\
\hline \multirow{12}{*}{ Sad } & \multirow{3}{*}{ Low-frequency } & Low-frequency/low-pressure & -0.30 & 0.10 & 0.03 \\
\hline & & Low-pressure & 0.05 & 0.10 & 1.00 \\
\hline & & Unaltered & 0.22 & 0.09 & 0.11 \\
\hline & \multirow{3}{*}{ Low-frequency/low-pressure } & Low-frequency & 0.30 & 0.10 & 0.03 \\
\hline & & Low-pressure & 0.35 & 0.11 & 0.01 \\
\hline & & Unaltered & 0.52 & 0.10 & $<0.01$ \\
\hline & \multirow{3}{*}{ Low-pressure } & Low-frequency & -0.05 & 0.10 & 1.00 \\
\hline & & Low-frequency/low-pressure & -0.35 & 0.11 & 0.01 \\
\hline & & Unaltered & 0.17 & 0.09 & 0.32 \\
\hline & \multirow{3}{*}{ Unaltered } & Low-frequency & -0.22 & 0.09 & 0.11 \\
\hline & & Low-frequency/low-pressure & -0.52 & 0.10 & $<0.01$ \\
\hline & & Low-pressure & -0.17 & 0.09 & 0.32 \\
\hline
\end{tabular}


Table A1. Cont.

\begin{tabular}{|c|c|c|c|c|c|}
\hline Measure & & & $\begin{array}{c}\text { Mean } \\
\text { Difference }\end{array}$ & Std. Error & $p$-Value \\
\hline \multirow{12}{*}{ Rational } & \multirow{3}{*}{ Low-frequency } & Low-frequency/low-pressure & 0.10 & 0.11 & 1.00 \\
\hline & & Low-pressure & 0.19 & 0.10 & 0.40 \\
\hline & & Unaltered & 0.07 & 0.12 & 1.00 \\
\hline & \multirow{3}{*}{ Low-frequency/low-pressure } & Low-frequency & -0.10 & 0.11 & 1.00 \\
\hline & & Low-pressure & 0.09 & 0.11 & 1.00 \\
\hline & & Unaltered & -0.03 & 0.11 & 1.00 \\
\hline & \multirow{3}{*}{ Low-pressure } & Low-frequency & -0.19 & 0.10 & 0.40 \\
\hline & & Low-frequency/low-pressure & -0.09 & 0.11 & 1.00 \\
\hline & & Unaltered & -0.12 & 0.12 & 1.00 \\
\hline & \multirow{3}{*}{ Unaltered } & Low-frequency & -0.07 & 0.12 & 1.00 \\
\hline & & Low-frequency/low-pressure & 0.03 & 0.11 & 1.00 \\
\hline & & Low-pressure & 0.12 & 0.12 & 1.00 \\
\hline \multirow{12}{*}{ Responsible } & \multirow{3}{*}{ Low-frequency } & Low-frequency/low-pressure & -0.10 & 0.11 & 1.00 \\
\hline & & Low-pressure & -0.08 & 0.10 & 1.00 \\
\hline & & Unaltered & 0.18 & 0.09 & 0.36 \\
\hline & \multirow{3}{*}{ Low-frequency/low-pressure } & Low-frequency & 0.10 & 0.11 & 1.00 \\
\hline & & Low-pressure & 0.02 & 0.10 & 1.00 \\
\hline & & Unaltered & 0.28 & 0.10 & 0.04 \\
\hline & \multirow{3}{*}{ Low-pressure } & Low-frequency & 0.08 & 0.10 & 1.00 \\
\hline & & Low-frequency/low-pressure & -0.02 & 0.10 & 1.00 \\
\hline & & Unaltered & 0.26 & 0.10 & 0.08 \\
\hline & \multirow{3}{*}{ Unaltered } & Low-frequency & -0.18 & 0.09 & 0.36 \\
\hline & & Low-frequency/low-pressure & -0.28 & 0.10 & 0.04 \\
\hline & & Low-pressure & -0.26 & 0.10 & 0.08 \\
\hline
\end{tabular}

Table A2. Summary of the results of the pairwise comparisons of Experiment 1 between-participants condition (sounds of packaging auditory experience) for emotion scores.

\begin{tabular}{|c|c|c|c|c|c|}
\hline Measure & & & Mean Difference & Std. Error & $p$-Value \\
\hline \multirow{12}{*}{ Amused } & \multirow{3}{*}{ Bottle opening } & Bottle pouring & -0.82 & 0.31 & 0.05 \\
\hline & & Can opening & 0.15 & 0.31 & 1.00 \\
\hline & & Can pouring & -0.22 & 0.31 & 1.00 \\
\hline & \multirow{3}{*}{ Bottle pouring } & Bottle opening & 0.82 & 0.31 & 0.05 \\
\hline & & Can opening & 0.97 & 0.31 & 0.01 \\
\hline & & Can pouring & 0.59 & 0.31 & 0.33 \\
\hline & \multirow{3}{*}{ Can opening } & Bottle opening & -0.15 & 0.31 & 1.00 \\
\hline & & Bottle pouring & -0.97 & 0.31 & 0.01 \\
\hline & & Can pouring & -0.38 & 0.31 & 1.00 \\
\hline & \multirow{3}{*}{ Can pouring } & Bottle opening & 0.22 & 0.31 & 1.00 \\
\hline & & Bottle pouring & -0.59 & 0.31 & 0.33 \\
\hline & & Can opening & 0.38 & 0.31 & 1.00 \\
\hline
\end{tabular}


Table A2. Cont.

\begin{tabular}{|c|c|c|c|c|c|}
\hline Measure & & & Mean Difference & Std. Error & $p$-Value \\
\hline \multirow{12}{*}{ Calmed } & \multirow{3}{*}{ Bottle opening } & Bottle pouring & -0.78 & 0.28 & 0.03 \\
\hline & & Can opening & 0.14 & 0.28 & 1.00 \\
\hline & & Can pouring & -0.16 & 0.28 & 1.00 \\
\hline & \multirow{3}{*}{ Bottle pouring } & Bottle opening & 0.78 & 0.28 & 0.03 \\
\hline & & Can opening & 0.92 & 0.28 & 0.01 \\
\hline & & Can pouring & 0.62 & 0.28 & 0.16 \\
\hline & \multirow{3}{*}{ Can opening } & Bottle opening & -0.14 & 0.28 & 1.00 \\
\hline & & Bottle pouring & -0.92 & 0.28 & 0.01 \\
\hline & & Can pouring & -0.30 & 0.28 & 1.00 \\
\hline & \multirow{3}{*}{ Can pouring } & Bottle opening & 0.16 & 0.28 & 1.00 \\
\hline & & Bottle pouring & -0.62 & 0.28 & 0.16 \\
\hline & & Can opening & 0.30 & 0.28 & 1.00 \\
\hline \multirow{12}{*}{ Comforted } & \multirow{3}{*}{ Bottle opening } & Bottle pouring & -1.09 & 0.29 & $<0.01$ \\
\hline & & Can opening & -0.07 & 0.29 & 1.00 \\
\hline & & Can pouring & -0.36 & 0.29 & 1.00 \\
\hline & \multirow{3}{*}{ Bottle pouring } & Bottle opening & 1.09 & 0.29 & $<0.01$ \\
\hline & & Can opening & 1.02 & 0.29 & $<0.01$ \\
\hline & & Can pouring & 0.72 & 0.29 & 0.07 \\
\hline & \multirow{3}{*}{ Can opening } & Bottle opening & 0.07 & 0.29 & 1.00 \\
\hline & & Bottle pouring & -1.02 & 0.29 & $<0.01$ \\
\hline & & Can pouring & -0.30 & 0.29 & 1.00 \\
\hline & \multirow{3}{*}{ Can pouring } & Bottle opening & 0.36 & 0.29 & 1.00 \\
\hline & & Bottle pouring & -0.72 & 0.29 & 0.07 \\
\hline & & Can opening & 0.30 & 0.29 & 1.00 \\
\hline \multirow{12}{*}{ Curious } & \multirow{3}{*}{ Bottle opening } & Bottle pouring & -0.64 & 0.31 & 0.24 \\
\hline & & Can opening & 0.07 & 0.31 & 1.00 \\
\hline & & Can pouring & -0.52 & 0.31 & 0.56 \\
\hline & \multirow{3}{*}{ Bottle pouring } & Bottle opening & 0.64 & 0.31 & 0.24 \\
\hline & & Can opening & 0.71 & 0.31 & 0.13 \\
\hline & & Can pouring & 0.12 & 0.31 & 1.00 \\
\hline & \multirow{3}{*}{ Can opening } & Bottle opening & -0.07 & 0.31 & 1.00 \\
\hline & & Bottle pouring & -0.71 & 0.31 & 0.13 \\
\hline & & Can pouring & -0.59 & 0.31 & 0.33 \\
\hline & \multirow{3}{*}{ Can pouring } & Bottle opening & 0.52 & 0.31 & 0.56 \\
\hline & & Bottle pouring & -0.12 & 0.31 & 1.00 \\
\hline & & Can opening & 0.59 & 0.31 & 0.33 \\
\hline \multirow{12}{*}{ Disappointed } & \multirow{3}{*}{ Bottle opening } & Bottle pouring & 0.39 & 0.25 & 0.72 \\
\hline & & Can opening & -0.64 & 0.25 & 0.07 \\
\hline & & Can pouring & -0.23 & 0.25 & 1.00 \\
\hline & \multirow{3}{*}{ Bottle pouring } & Bottle opening & -0.39 & 0.25 & 0.72 \\
\hline & & Can opening & -10.03 & 0.25 & $<0.01$ \\
\hline & & Can pouring & -0.62 & 0.25 & 0.08 \\
\hline & \multirow{3}{*}{ Can opening } & Bottle opening & 0.64 & 0.25 & 0.07 \\
\hline & & Bottle pouring & 10.03 & 0.25 & $<0.01$ \\
\hline & & Can pouring & 0.41 & 0.25 & 0.61 \\
\hline & \multirow{3}{*}{ Can pouring } & Bottle opening & 0.23 & 0.25 & 1.00 \\
\hline & & Bottle pouring & 0.62 & 0.25 & 0.08 \\
\hline & & Can opening & -0.41 & 0.25 & 0.61 \\
\hline
\end{tabular}


Table A2. Cont.

\begin{tabular}{|c|c|c|c|c|c|}
\hline Measure & & & Mean Difference & Std. Error & $p$-Value \\
\hline \multirow{12}{*}{ Energetic } & \multirow{3}{*}{ Bottle opening } & Bottle pouring & -0.25 & 0.31 & 1.00 \\
\hline & & Can opening & 0.47 & 0.31 & 0.76 \\
\hline & & Can pouring & 0.16 & 0.31 & 1.00 \\
\hline & \multirow{3}{*}{ Bottle pouring } & Bottle opening & 0.25 & 0.31 & 1.00 \\
\hline & & Can opening & 0.72 & 0.31 & 0.12 \\
\hline & & Can pouring & 0.41 & 0.31 & 1.00 \\
\hline & \multirow{3}{*}{ Can opening } & Bottle opening & -0.47 & 0.31 & 0.76 \\
\hline & & Bottle pouring & -0.72 & 0.31 & 0.12 \\
\hline & & Can pouring & -0.31 & 0.31 & 1.00 \\
\hline & \multirow{3}{*}{ Can pouring } & Bottle opening & -0.16 & 0.31 & 1.00 \\
\hline & & Bottle pouring & -0.41 & 0.31 & 1.00 \\
\hline & & Can opening & 0.31 & 0.31 & 1.00 \\
\hline \multirow{12}{*}{ Excited } & \multirow{3}{*}{ Bottle opening } & Bottle pouring & -0.74 & 0.31 & 0.11 \\
\hline & & Can opening & 0.37 & 0.31 & 1.00 \\
\hline & & Can pouring & 0.22 & 0.31 & 1.00 \\
\hline & \multirow{3}{*}{ Bottle pouring } & Bottle opening & 0.74 & 0.31 & 0.11 \\
\hline & & Can opening & 10.11 & 0.31 & $<0.01$ \\
\hline & & Can pouring & 0.96 & 0.31 & 0.01 \\
\hline & \multirow{3}{*}{ Can opening } & Bottle opening & -0.37 & 0.31 & 1.00 \\
\hline & & Bottle pouring & -1.11 & 0.31 & $<0.01$ \\
\hline & & Can pouring & -0.15 & 0.31 & 1.00 \\
\hline & \multirow{3}{*}{ Can pouring } & Bottle opening & -0.22 & 0.31 & 1.00 \\
\hline & & Bottle pouring & -0.96 & 0.31 & 0.01 \\
\hline & & Can opening & 0.15 & 0.31 & 1.00 \\
\hline \multirow{12}{*}{ Friendly } & \multirow{3}{*}{ Bottle opening } & Bottle pouring & -0.77 & 0.32 & 0.09 \\
\hline & & Can opening & 0.35 & 0.32 & 1.00 \\
\hline & & Can pouring & -0.05 & 0.32 & 1.00 \\
\hline & \multirow{3}{*}{ Bottle pouring } & Bottle opening & 0.77 & 0.32 & 0.09 \\
\hline & & Can opening & 1.12 & 0.32 & $<0.01$ \\
\hline & & Can pouring & 0.72 & 0.32 & 0.14 \\
\hline & \multirow{3}{*}{ Can opening } & Bottle opening & -0.35 & 0.32 & 1.00 \\
\hline & & Bottle pouring & -1.12 & 0.32 & $<0.01$ \\
\hline & & Can pouring & -0.40 & 0.32 & 1.00 \\
\hline & \multirow{3}{*}{ Can pouring } & Bottle opening & 0.05 & 0.32 & 1.00 \\
\hline & & Bottle pouring & -0.72 & 0.32 & 0.14 \\
\hline & & Can opening & 0.40 & 0.32 & 1.00 \\
\hline \multirow{12}{*}{ Good } & \multirow{3}{*}{ Bottle opening } & Bottle pouring & -0.74 & 0.27 & 0.04 \\
\hline & & Can opening & 0.50 & 0.27 & 0.39 \\
\hline & & Can pouring & -0.02 & 0.27 & 1.00 \\
\hline & \multirow{3}{*}{ Bottle pouring } & Bottle opening & 0.74 & 0.27 & 0.04 \\
\hline & & Can opening & 1.24 & 0.27 & $<0.01$ \\
\hline & & Can pouring & 0.72 & 0.27 & 0.05 \\
\hline & \multirow{3}{*}{ Can opening } & Bottle opening & -0.50 & 0.27 & 0.39 \\
\hline & & Bottle pouring & -1.24 & 0.27 & $<0.01$ \\
\hline & & Can pouring & -0.52 & 0.27 & 0.35 \\
\hline & \multirow{3}{*}{ Can pouring } & Bottle opening & 0.02 & 0.27 & 1.00 \\
\hline & & Bottle pouring & -0.72 & 0.27 & 0.05 \\
\hline & & Can opening & 0.52 & 0.27 & 0.35 \\
\hline
\end{tabular}


Table A2. Cont.

\begin{tabular}{|c|c|c|c|c|c|}
\hline Measure & & & Mean Difference & Std. Error & $p$-Value \\
\hline \multirow{12}{*}{ Grumpy } & \multirow{3}{*}{ Bottle opening } & Bottle pouring & 0.30 & 0.22 & 1.00 \\
\hline & & Can opening & -0.24 & 0.22 & 1.00 \\
\hline & & Can pouring & -0.46 & 0.22 & 0.23 \\
\hline & \multirow{3}{*}{ Bottle pouring } & Bottle opening & -0.30 & 0.22 & 1.00 \\
\hline & & Can opening & -0.54 & 0.22 & 0.10 \\
\hline & & Can pouring & -0.76 & 0.22 & $<0.01$ \\
\hline & \multirow{3}{*}{ Can opening } & Bottle opening & 0.24 & 0.22 & 1.00 \\
\hline & & Bottle pouring & 0.54 & 0.22 & 0.10 \\
\hline & & Can pouring & -0.22 & 0.22 & 1.00 \\
\hline & \multirow{3}{*}{ Can pouring } & Bottle opening & 0.46 & 0.22 & 0.23 \\
\hline & & Bottle pouring & 0.76 & 0.22 & $<0.01$ \\
\hline & & Can opening & 0.22 & 0.22 & 1.00 \\
\hline \multirow{12}{*}{ Joyful } & \multirow{3}{*}{ Bottle opening } & Bottle pouring & -0.61 & 0.31 & 0.28 \\
\hline & & Can opening & 0.31 & 0.31 & 1.00 \\
\hline & & Can pouring & 0.08 & 0.31 & 1.00 \\
\hline & \multirow{3}{*}{ Bottle pouring } & Bottle opening & 0.61 & 0.31 & 0.28 \\
\hline & & Can opening & 0.92 & 0.31 & 0.02 \\
\hline & & Can pouring & 0.69 & 0.31 & 0.15 \\
\hline & \multirow{3}{*}{ Can opening } & Bottle opening & -0.31 & 0.31 & 1.00 \\
\hline & & Bottle pouring & -0.92 & 0.31 & 0.02 \\
\hline & & Can pouring & -0.23 & 0.31 & 1.00 \\
\hline & \multirow{3}{*}{ Can pouring } & Bottle opening & -0.08 & 0.31 & 1.00 \\
\hline & & Bottle pouring & -0.69 & 0.31 & 0.15 \\
\hline & & Can opening & 0.23 & 0.31 & 1.00 \\
\hline \multirow{12}{*}{ Pleased } & \multirow{3}{*}{ Bottle opening } & Bottle pouring & -1.08 & 0.29 & $<0.01$ \\
\hline & & Can opening & 0.22 & 0.29 & 1.00 \\
\hline & & Can pouring & -0.15 & 0.29 & 1.00 \\
\hline & \multirow{3}{*}{ Bottle pouring } & Bottle opening & 1.08 & 0.29 & $<0.01$ \\
\hline & & Can opening & 1.30 & 0.29 & $<0.01$ \\
\hline & & Can pouring & 0.93 & 0.29 & 0.01 \\
\hline & \multirow{3}{*}{ Can opening } & Bottle opening & -0.22 & 0.29 & 1.00 \\
\hline & & Bottle pouring & -1.30 & 0.29 & $<0.01$ \\
\hline & & Can pouring & -0.37 & 0.29 & 1.00 \\
\hline & \multirow{3}{*}{ Can pouring } & Bottle opening & 0.15 & 0.29 & 1.00 \\
\hline & & Bottle pouring & -0.93 & 0.29 & 0.01 \\
\hline & & Can opening & 0.37 & 0.29 & 1.00 \\
\hline \multirow{12}{*}{ Restless } & \multirow{3}{*}{ Bottle opening } & Bottle pouring & 0.27 & 0.25 & 1.00 \\
\hline & & Can opening & -0.27 & 0.25 & 1.00 \\
\hline & & Can pouring & -0.61 & 0.25 & 0.09 \\
\hline & \multirow{3}{*}{ Bottle pouring } & Bottle opening & -0.27 & 0.25 & 1.00 \\
\hline & & Can opening & -0.54 & 0.25 & 0.20 \\
\hline & & Can pouring & -0.89 & 0.25 & $<0.01$ \\
\hline & \multirow{3}{*}{ Can opening } & Bottle opening & 0.27 & 0.25 & 1.00 \\
\hline & & Bottle pouring & 0.54 & 0.25 & 0.20 \\
\hline & & Can pouring & -0.35 & 0.25 & 1.00 \\
\hline & \multirow{3}{*}{ Can pouring } & Bottle opening & 0.61 & 0.25 & 0.09 \\
\hline & & Bottle pouring & 0.89 & 0.25 & $<0.01$ \\
\hline & & Can opening & 0.35 & 0.25 & 1.00 \\
\hline
\end{tabular}


Table A2. Cont.

\begin{tabular}{|c|c|c|c|c|c|}
\hline Measure & & & Mean Difference & Std. Error & $p$-Value \\
\hline \multirow{12}{*}{ Sad } & \multirow{3}{*}{ Bottle opening } & Bottle pouring & 0.24 & 0.20 & 1.00 \\
\hline & & Can opening & -0.24 & 0.20 & 1.00 \\
\hline & & Can pouring & -0.25 & 0.20 & 1.00 \\
\hline & \multirow{3}{*}{ Bottle pouring } & Bottle opening & -0.24 & 0.20 & 1.00 \\
\hline & & Can opening & -0.48 & 0.20 & 0.09 \\
\hline & & Can pouring & -0.49 & 0.20 & 0.08 \\
\hline & \multirow{3}{*}{ Can opening } & Bottle opening & 0.24 & 0.20 & 1.00 \\
\hline & & Bottle pouring & 0.48 & 0.20 & 0.09 \\
\hline & & Can pouring & -0.01 & 0.20 & 1.00 \\
\hline & \multirow{3}{*}{ Can pouring } & Bottle opening & 0.25 & 0.20 & 1.00 \\
\hline & & Bottle pouring & 0.49 & 0.20 & 0.08 \\
\hline & & Can opening & 0.01 & 0.20 & 1.00 \\
\hline \multirow{12}{*}{ Rational } & \multirow{3}{*}{ Bottle opening } & Bottle pouring & -0.52 & 0.28 & 0.37 \\
\hline & & Can opening & -0.05 & 0.28 & 1.00 \\
\hline & & Can pouring & -0.71 & 0.28 & 0.07 \\
\hline & \multirow{3}{*}{ Bottle pouring } & Bottle opening & 0.52 & 0.28 & 0.37 \\
\hline & & Can opening & 0.47 & 0.28 & 0.56 \\
\hline & & Can pouring & -0.19 & 0.28 & 1.00 \\
\hline & \multirow{3}{*}{ Can opening } & Bottle opening & 0.05 & 0.28 & 1.00 \\
\hline & & Bottle pouring & -0.47 & 0.28 & 0.56 \\
\hline & & Can pouring & -0.66 & 0.28 & 0.12 \\
\hline & \multirow{3}{*}{ Can pouring } & Bottle opening & 0.71 & 0.28 & 0.07 \\
\hline & & Bottle pouring & 0.19 & 0.28 & 1.00 \\
\hline & & Can opening & 0.66 & 0.28 & 0.12 \\
\hline \multirow{12}{*}{ Responsible } & \multirow{3}{*}{ Bottle opening } & Bottle pouring & -0.49 & 0.29 & 0.53 \\
\hline & & Can opening & -0.01 & 0.29 & 1.00 \\
\hline & & Can pouring & -0.21 & 0.29 & 1.00 \\
\hline & \multirow{3}{*}{ Bottle pouring } & Bottle opening & 0.49 & 0.29 & 0.53 \\
\hline & & Can opening & 0.48 & 0.29 & 0.55 \\
\hline & & Can pouring & 0.28 & 0.29 & 1.00 \\
\hline & \multirow{3}{*}{ Can opening } & Bottle opening & 0.01 & 0.29 & 1.00 \\
\hline & & Bottle pouring & -0.48 & 0.29 & 0.55 \\
\hline & & Can pouring & -0.21 & 0.29 & 1.00 \\
\hline & \multirow{3}{*}{ Can pouring } & Bottle opening & 0.21 & 0.29 & 1.00 \\
\hline & & Bottle pouring & -0.28 & 0.29 & 1.00 \\
\hline & & Can opening & 0.21 & 0.29 & 1.00 \\
\hline
\end{tabular}

Table A3. Summary of the results of the pairwise comparisons of Experiment 1 within-participants condition (sound manipulation) for sensory expectations.

\begin{tabular}{|c|c|c|c|c|c|}
\hline Measure & & & $\begin{array}{c}\text { Mean } \\
\text { Difference }\end{array}$ & Std. Error & $p$-Value \\
\hline \multirow{9}{*}{ Alcohol } & \multirow{3}{*}{ Low-frequency } & Low-frequency/low-pressure & 0.50 & 0.13 & $<0.01$ \\
\hline & & Low-pressure & 0.56 & 0.13 & $<0.01$ \\
\hline & & Unaltered & 0.08 & 0.10 & 1.00 \\
\hline & \multirow{3}{*}{ Low-frequency/low-pressure } & Low-frequency & -0.50 & 0.13 & $<0.01$ \\
\hline & & Low-pressure & 0.06 & 0.10 & 1.00 \\
\hline & & Unaltered & -0.42 & 0.12 & $<0.01$ \\
\hline & \multirow{3}{*}{ Low-pressure } & Low-frequency & -0.56 & 0.13 & $<0.01$ \\
\hline & & Low-frequency/low-pressure & -0.06 & 0.10 & 1.00 \\
\hline & & Unaltered & -0.48 & 0.11 & $<0.01$ \\
\hline
\end{tabular}


Table A3. Cont.

\begin{tabular}{|c|c|c|c|c|c|}
\hline \multirow[t]{4}{*}{ Measure } & \multicolumn{2}{|c|}{ Stimuli } & $\begin{array}{c}\text { Mean } \\
\text { Difference }\end{array}$ & Std. Error & $p$-Value \\
\hline & \multirow{3}{*}{ Unaltered } & Low-frequency & -0.08 & 0.10 & 1.00 \\
\hline & & Low-frequency/low-pressure & 0.42 & 0.12 & $<0.01$ \\
\hline & & Low-pressure & 0.48 & 0.11 & $<0.01$ \\
\hline \multirow{12}{*}{ Refreshing } & \multirow{3}{*}{ Low-frequency } & Low-frequency/low-pressure & 1.00 & 0.17 & $<0.01$ \\
\hline & & Low-pressure & 0.45 & 0.15 & 0.02 \\
\hline & & Unaltered & -0.14 & 0.13 & 1.00 \\
\hline & \multirow{3}{*}{ Low-frequency/low-pressure } & Low-frequency & -1.00 & 0.17 & $<0.01$ \\
\hline & & Low-pressure & -0.54 & 0.13 & $<0.01$ \\
\hline & & Unaltered & -1.13 & 0.16 & $<0.01$ \\
\hline & \multirow{3}{*}{ Low-pressure } & Low-frequency & -0.45 & 0.15 & 0.02 \\
\hline & & Low-frequency/low-pressure & 0.54 & 0.13 & $<0.01$ \\
\hline & & Unaltered & -0.59 & 0.15 & $<0.01$ \\
\hline & \multirow{3}{*}{ Unaltered } & Low-frequency & 0.14 & 0.13 & 1.00 \\
\hline & & Low-frequency/low-pressure & 1.13 & 0.16 & $<0.01$ \\
\hline & & Low-pressure & 0.59 & 0.15 & $<0.01$ \\
\hline \multirow{12}{*}{ Sweetness } & \multirow{3}{*}{ Low-frequency } & Low-frequency/low-pressure & -0.12 & 0.13 & 1.00 \\
\hline & & Low-pressure & -0.44 & 0.14 & 0.02 \\
\hline & & Unaltered & -0.26 & 0.12 & 0.21 \\
\hline & \multirow{3}{*}{ Low-frequency/low-pressure } & Low-frequency & 0.12 & 0.13 & 1.00 \\
\hline & & Low-pressure & -0.32 & 0.14 & 0.12 \\
\hline & & Unaltered & -0.14 & 0.13 & 1.00 \\
\hline & \multirow{3}{*}{ Low-pressure } & Low-frequency & 0.44 & 0.14 & 0.02 \\
\hline & & Low-frequency/low-pressure & 0.32 & 0.14 & 0.12 \\
\hline & & Unaltered & 0.18 & 0.14 & 1.00 \\
\hline & \multirow{3}{*}{ Unaltered } & Low-frequency & 0.26 & 0.12 & 0.21 \\
\hline & & Low-frequency/low-pressure & 0.14 & 0.13 & 1.00 \\
\hline & & Low-pressure & -0.18 & 0.14 & 1.00 \\
\hline \multirow{12}{*}{ Bitterness } & \multirow{3}{*}{ Low-frequency } & Low-frequency/low-pressure & 0.20 & 0.14 & 1.00 \\
\hline & & Low-pressure & 0.49 & 0.15 & 0.01 \\
\hline & & Unaltered & 0.27 & 0.14 & 0.33 \\
\hline & \multirow{3}{*}{ Low-frequency/low-pressure } & Low-frequency & -0.20 & 0.14 & 1.00 \\
\hline & & Low-pressure & 0.29 & 0.15 & 0.28 \\
\hline & & Unaltered & 0.07 & 0.15 & 1.00 \\
\hline & \multirow{3}{*}{ Low-pressure } & Low-frequency & -0.49 & 0.15 & 0.01 \\
\hline & & Low-frequency/low-pressure & -0.29 & 0.15 & 0.28 \\
\hline & & Unaltered & -0.22 & 0.15 & 0.77 \\
\hline & \multirow{3}{*}{ Unaltered } & Low-frequency & -0.27 & 0.14 & 0.33 \\
\hline & & Low-frequency/low-pressure & -0.07 & 0.15 & 1.00 \\
\hline & & Low-pressure & 0.22 & 0.15 & 0.77 \\
\hline
\end{tabular}

Table A4. Summary of the results of the pairwise comparisons of Experiment 1 between-participants condition (sounds of packaging auditory experience) for sensory expectations.

\begin{tabular}{|c|c|c|c|c|c|}
\hline Measure & & & Mean Difference & Std. Error & $p$-Value \\
\hline \multirow{6}{*}{ Alcohol } & \multirow{3}{*}{ Bottle opening } & Bottle pouring & 0.07 & 0.33 & 1.00 \\
\hline & & Can opening & 0.39 & 0.33 & 1.00 \\
\hline & & Can pouring & -0.12 & 0.33 & 1.00 \\
\hline & \multirow{3}{*}{ Bottle pouring } & Bottle opening & -0.07 & 0.33 & 1.00 \\
\hline & & Can opening & 0.32 & 0.33 & 1.00 \\
\hline & & Can pouring & -0.19 & 0.33 & 1.00 \\
\hline
\end{tabular}


Table A4. Cont.

\begin{tabular}{|c|c|c|c|c|c|}
\hline \multirow[t]{7}{*}{ Measure } & \multicolumn{2}{|c|}{ Stimuli } & \multirow{2}{*}{$\begin{array}{c}\text { Mean Difference } \\
-0.39\end{array}$} & \multirow{2}{*}{$\begin{array}{c}\text { Std. Error } \\
0.33\end{array}$} & \multirow{2}{*}{$\frac{p \text {-Value }}{1.00}$} \\
\hline & & Bottle opening & & & \\
\hline & Can opening & Bottle pouring & -0.32 & 0.33 & 1.00 \\
\hline & & Can pouring & -0.51 & 0.33 & 0.75 \\
\hline & & Bottle opening & 0.12 & 0.33 & 1.00 \\
\hline & Can pouring & Bottle pouring & 0.19 & 0.33 & 1.00 \\
\hline & & Can opening & 0.51 & 0.33 & 0.75 \\
\hline \multirow{12}{*}{ Refreshing } & \multirow{3}{*}{ Bottle opening } & Bottle pouring & -1.09 & 0.28 & $<0.01$ \\
\hline & & Can opening & 0.33 & 0.28 & 1.00 \\
\hline & & Can pouring & -0.34 & 0.28 & 1.00 \\
\hline & \multirow{3}{*}{ Bottle pouring } & Bottle opening & 1.09 & 0.28 & $<0.01$ \\
\hline & & Can opening & 1.42 & 0.28 & $<0.01$ \\
\hline & & Can pouring & 0.75 & 0.28 & 0.05 \\
\hline & \multirow{3}{*}{ Can opening } & Bottle opening & -0.33 & 0.28 & 1.00 \\
\hline & & Bottle pouring & -1.42 & 0.28 & $<0.01$ \\
\hline & & Can pouring & -0.67 & 0.28 & 0.10 \\
\hline & \multirow{3}{*}{ Can pouring } & Bottle opening & 0.34 & 0.28 & 1.00 \\
\hline & & Bottle pouring & -0.75 & 0.28 & 0.05 \\
\hline & & Can opening & 0.67 & 0.28 & 0.10 \\
\hline \multirow{12}{*}{ Sweetness } & \multirow{3}{*}{ Bottle opening } & Bottle pouring & -0.35 & 0.27 & 1.00 \\
\hline & & Can opening & -0.27 & 0.27 & 1.00 \\
\hline & & Can pouring & -0.69 & 0.27 & 0.06 \\
\hline & \multirow{3}{*}{ Bottle pouring } & Bottle opening & 0.35 & 0.27 & 1.00 \\
\hline & & Can opening & 0.08 & 0.27 & 1.00 \\
\hline & & Can pouring & -0.34 & 0.27 & 1.00 \\
\hline & \multirow{3}{*}{ Can opening } & Bottle opening & 0.27 & 0.27 & 1.00 \\
\hline & & Bottle pouring & -0.08 & 0.27 & 1.00 \\
\hline & & Can pouring & -0.42 & 0.27 & 0.69 \\
\hline & \multirow{3}{*}{ Can pouring } & Bottle opening & 0.69 & 0.27 & 0.06 \\
\hline & & Bottle pouring & 0.34 & 0.27 & 1.00 \\
\hline & & Can opening & 0.42 & 0.27 & 0.69 \\
\hline \multirow{12}{*}{ Bitterness } & \multirow{3}{*}{ Bottle opening } & Bottle pouring & -0.20 & 0.30 & 1.00 \\
\hline & & Can opening & -0.10 & 0.30 & 1.00 \\
\hline & & Can pouring & -0.61 & 0.30 & 0.26 \\
\hline & \multirow{3}{*}{ Bottle pouring } & Bottle opening & 0.20 & 0.30 & 1.00 \\
\hline & & Can opening & 0.10 & 0.30 & 1.00 \\
\hline & & Can pouring & -0.41 & 0.30 & 1.00 \\
\hline & \multirow{3}{*}{ Can opening } & Bottle opening & 0.10 & 0.30 & 1.00 \\
\hline & & Bottle pouring & -0.10 & 0.30 & 1.00 \\
\hline & & Can pouring & -0.51 & 0.30 & 0.56 \\
\hline & \multirow{3}{*}{ Can pouring } & Bottle opening & 0.61 & 0.30 & 0.26 \\
\hline & & Bottle pouring & 0.41 & 0.30 & 1.00 \\
\hline & & Can opening & 0.51 & 0.30 & 0.56 \\
\hline
\end{tabular}

Table A5. Summary of the results of the pairwise comparisons of auditory conditions for emotion scores in Experiment 2.

\begin{tabular}{cccccc}
\hline Measure & & Stimuli & Mean Difference & Std. Error & $p$-Value \\
\hline \multirow{3}{*}{ Amused } & \multirow{2}{*}{ No sound } & Unaltered & -0.47 & 0.24 & 0.32 \\
& & Low-frequency & -0.22 & 0.24 & 1.00 \\
& & Low-pressure & -0.35 & 0.24 & 0.89 \\
\hline
\end{tabular}


Table A5. Cont.

\begin{tabular}{|c|c|c|c|c|c|}
\hline \multirow[t]{10}{*}{ Measure } & \multicolumn{2}{|c|}{ Stimuli } & \multirow{2}{*}{$\begin{array}{c}\text { Mean Difference } \\
0.47\end{array}$} & \multirow{2}{*}{$\begin{array}{c}\text { Std. Error } \\
0.24\end{array}$} & \multirow{2}{*}{$\begin{array}{c}p \text {-Value } \\
0.32\end{array}$} \\
\hline & & No sound & & & \\
\hline & Unaltered & Low-frequency & 0.25 & 0.24 & 1.00 \\
\hline & & Low-pressure & 0.12 & 0.24 & 1.00 \\
\hline & & No sound & 0.22 & 0.24 & 1.00 \\
\hline & Low-frequency & Unaltered & -0.25 & 0.24 & 1.00 \\
\hline & & Low-pressure & -0.13 & 0.24 & 1.00 \\
\hline & & No sound & 0.35 & 0.24 & 0.89 \\
\hline & Low-pressure & Unaltered & -0.12 & 0.24 & 1.00 \\
\hline & & Low-frequency & 0.13 & 0.24 & 1.00 \\
\hline \multirow{12}{*}{ Calmed } & & Unaltered & -1.22 & 0.23 & $<0.01$ \\
\hline & No sound & Low-frequency & -1.09 & 0.23 & $<0.01$ \\
\hline & & Low-pressure & -1.30 & 0.23 & $<0.01$ \\
\hline & & No sound & 1.22 & 0.23 & $<0.01$ \\
\hline & Unaltered & Low-frequency & 0.12 & 0.23 & 1.00 \\
\hline & & Low-pressure & -0.08 & 0.23 & 1.00 \\
\hline & & No sound & 1.09 & 0.23 & $<0.01$ \\
\hline & Low-frequency & Unaltered & -0.12 & 0.23 & 1.00 \\
\hline & & Low-pressure & -0.20 & 0.23 & 1.00 \\
\hline & & No sound & 1.30 & 0.23 & $<0.01$ \\
\hline & Low-pressure & Unaltered & 0.08 & 0.23 & 1.00 \\
\hline & & Low-frequency & 0.20 & 0.23 & 1.00 \\
\hline \multirow{12}{*}{ Comforted } & & Unaltered & -1.00 & 0.22 & $<0.01$ \\
\hline & No sound & Low-frequency & -0.91 & 0.22 & $<0.01$ \\
\hline & & Low-pressure & -1.12 & 0.22 & $<0.01$ \\
\hline & & No sound & 1.00 & 0.22 & $<0.01$ \\
\hline & Unaltered & Low-frequency & 0.09 & 0.22 & 1.00 \\
\hline & & Low-pressure & -0.12 & 0.22 & 1.00 \\
\hline & & No sound & 0.91 & 0.22 & $<0.01$ \\
\hline & Low-frequency & Unaltered & -0.09 & 0.22 & 1.00 \\
\hline & & Low-pressure & -0.21 & 0.22 & 1.00 \\
\hline & & No sound & 1.12 & 0.22 & $<0.01$ \\
\hline & Low-pressure & Unaltered & 0.12 & 0.22 & 1.00 \\
\hline & & Low-frequency & 0.21 & 0.22 & 1.00 \\
\hline \multirow{12}{*}{ Curious } & & Unaltered & -0.10 & 0.24 & 1.00 \\
\hline & No sound & Low-frequency & -0.04 & 0.24 & 1.00 \\
\hline & & Low-pressure & -0.13 & 0.24 & 1.00 \\
\hline & & No sound & 0.10 & 0.24 & 1.00 \\
\hline & Unaltered & Low-frequency & 0.06 & 0.24 & 1.00 \\
\hline & & Low-pressure & -0.03 & 0.24 & 1.00 \\
\hline & & No sound & 0.04 & 0.24 & 1.00 \\
\hline & Low-frequency & Unaltered & -0.06 & 0.24 & 1.00 \\
\hline & & Low-pressure & -0.09 & 0.24 & 1.00 \\
\hline & & No sound & 0.13 & 0.24 & 1.00 \\
\hline & Low-pressure & Unaltered & 0.03 & 0.24 & 1.00 \\
\hline & & Low-frequency & 0.09 & 0.24 & 1.00 \\
\hline
\end{tabular}


Table A5. Cont.

\begin{tabular}{|c|c|c|c|c|c|}
\hline Measure & & & Mean Difference & Std. Error & $p$-Value \\
\hline \multirow{12}{*}{ Disappointed } & \multirow{3}{*}{ No sound } & Unaltered & 0.72 & 0.18 & $<0.01$ \\
\hline & & Low-frequency & 0.70 & 0.18 & $<0.01$ \\
\hline & & Low-pressure & 0.75 & 0.18 & $<0.01$ \\
\hline & \multirow{3}{*}{ Unaltered } & No sound & -0.72 & 0.18 & $<0.01$ \\
\hline & & Low-frequency & -0.01 & 0.18 & 1.00 \\
\hline & & Low-pressure & 0.03 & 0.18 & 1.00 \\
\hline & \multirow{3}{*}{ Low-frequency } & No sound & -0.70 & 0.18 & $<0.01$ \\
\hline & & Unaltered & 0.01 & 0.18 & 1.00 \\
\hline & & Low-pressure & 0.05 & 0.18 & 1.00 \\
\hline & \multirow{3}{*}{ Low-pressure } & No sound & -0.75 & 0.18 & $<0.01$ \\
\hline & & Unaltered & -0.03 & 0.18 & 1.00 \\
\hline & & Low-frequency & -0.05 & 0.18 & 1.00 \\
\hline \multirow{12}{*}{ Energetic } & \multirow{3}{*}{ No sound } & Unaltered & -0.26 & 0.22 & 1.00 \\
\hline & & Low-frequency & -0.48 & 0.22 & 0.17 \\
\hline & & Low-pressure & -0.23 & 0.22 & 1.00 \\
\hline & \multirow{3}{*}{ Unaltered } & No sound & 0.26 & 0.22 & 1.00 \\
\hline & & Low-frequency & -0.22 & 0.22 & 1.00 \\
\hline & & Low-pressure & 0.03 & 0.22 & 1.00 \\
\hline & \multirow{3}{*}{ Low-frequency } & No sound & 0.48 & 0.22 & 0.17 \\
\hline & & Unaltered & 0.22 & 0.22 & 1.00 \\
\hline & & Low-pressure & 0.25 & 0.22 & 1.00 \\
\hline & \multirow{3}{*}{ Low-pressure } & No sound & 0.23 & 0.22 & 1.00 \\
\hline & & Unaltered & -0.03 & 0.22 & 1.00 \\
\hline & & Low-frequency & -0.25 & 0.22 & 1.00 \\
\hline \multirow{12}{*}{ Excited } & \multirow{3}{*}{ No sound } & Unaltered & -0.80 & 0.23 & $<0.01$ \\
\hline & & Low-frequency & -0.46 & 0.23 & 0.29 \\
\hline & & Low-pressure & -0.79 & 0.23 & $<0.01$ \\
\hline & \multirow{3}{*}{ Unaltered } & No sound & 0.80 & 0.23 & $<0.01$ \\
\hline & & Low-frequency & 0.34 & 0.23 & 0.86 \\
\hline & & Low-pressure & 0.01 & 0.23 & 1.00 \\
\hline & \multirow{3}{*}{ Low-frequency } & No sound & 0.46 & 0.23 & 0.29 \\
\hline & & Unaltered & -0.34 & 0.23 & 0.86 \\
\hline & & Low-pressure & -0.33 & 0.23 & 0.93 \\
\hline & \multirow{3}{*}{ Low-pressure } & No sound & 0.79 & 0.23 & $<0.01$ \\
\hline & & Unaltered & -0.01 & 0.23 & 1.00 \\
\hline & & Low-frequency & 0.33 & 0.23 & 0.93 \\
\hline \multirow{12}{*}{ Friendly } & \multirow{3}{*}{ No sound } & Unaltered & -0.42 & 0.21 & 0.30 \\
\hline & & Low-frequency & -0.41 & 0.21 & 0.34 \\
\hline & & Low-pressure & -0.61 & 0.21 & 0.03 \\
\hline & \multirow{3}{*}{ Unaltered } & No sound & 0.42 & 0.21 & 0.30 \\
\hline & & Low-frequency & 0.01 & 0.21 & 1.00 \\
\hline & & Low-pressure & -0.20 & 0.21 & 1.00 \\
\hline & \multirow{3}{*}{ Low-frequency } & No sound & 0.41 & 0.21 & 0.34 \\
\hline & & Unaltered & -0.01 & 0.21 & 1.00 \\
\hline & & Low-pressure & -0.20 & 0.21 & 1.00 \\
\hline & \multirow{3}{*}{ Low-pressure } & No sound & 0.61 & 0.21 & 0.03 \\
\hline & & Unaltered & 0.20 & 0.21 & 1.00 \\
\hline & & Low-frequency & 0.20 & 0.21 & 1.00 \\
\hline
\end{tabular}


Table A5. Cont.

\begin{tabular}{|c|c|c|c|c|c|}
\hline Measure & & & Mean Difference & Std. Error & $p$-Value \\
\hline \multirow{12}{*}{ Good } & \multirow{3}{*}{ No sound } & Unaltered & -0.76 & 0.20 & $<0.01$ \\
\hline & & Low-frequency & -0.62 & 0.20 & 0.01 \\
\hline & & Low-pressure & -0.65 & 0.20 & 0.01 \\
\hline & \multirow{3}{*}{ Unaltered } & No sound & 0.76 & 0.20 & $<0.01$ \\
\hline & & Low-frequency & 0.15 & 0.20 & 1.00 \\
\hline & & Low-pressure & 0.11 & 0.20 & 1.00 \\
\hline & \multirow{3}{*}{ Low-frequency } & No sound & 0.62 & 0.20 & 0.01 \\
\hline & & Unaltered & -0.15 & 0.20 & 1.00 \\
\hline & & Low-pressure & -0.04 & 0.20 & 1.00 \\
\hline & \multirow{3}{*}{ Low-pressure } & No sound & 0.65 & 0.20 & 0.01 \\
\hline & & Unaltered & -0.11 & 0.20 & 1.00 \\
\hline & & Low-frequency & 0.04 & 0.20 & 1.00 \\
\hline \multirow{12}{*}{ Grumpy } & \multirow{3}{*}{ No sound } & Unaltered & 0.81 & 0.19 & $<0.01$ \\
\hline & & Low-frequency & 0.41 & 0.19 & 0.18 \\
\hline & & Low-pressure & 0.52 & 0.19 & 0.04 \\
\hline & \multirow{3}{*}{ Unaltered } & No sound & -0.81 & 0.19 & $<0.01$ \\
\hline & & Low-frequency & -0.40 & 0.19 & 0.21 \\
\hline & & Low-pressure & -0.29 & 0.19 & 0.76 \\
\hline & \multirow{3}{*}{ Low-frequency } & No sound & -0.41 & 0.19 & 0.18 \\
\hline & & Unaltered & 0.40 & 0.19 & 0.21 \\
\hline & & Low-pressure & 0.11 & 0.19 & 1.00 \\
\hline & \multirow{3}{*}{ Low-pressure } & No sound & -0.52 & 0.19 & 0.04 \\
\hline & & Unaltered & 0.29 & 0.19 & 0.76 \\
\hline & & Low-frequency & -0.11 & 0.19 & 1.00 \\
\hline \multirow{12}{*}{ Joyful } & \multirow{3}{*}{ No sound } & Unaltered & -0.75 & 0.22 & $<0.01$ \\
\hline & & Low-frequency & -0.74 & 0.22 & 0.01 \\
\hline & & Low-pressure & -0.87 & 0.22 & $<0.01$ \\
\hline & \multirow{3}{*}{ Unaltered } & No sound & 0.75 & 0.22 & $<0.01$ \\
\hline & & Low-frequency & 0.01 & 0.22 & 1.00 \\
\hline & & Low-pressure & -0.12 & 0.22 & 1.00 \\
\hline & \multirow{3}{*}{ Low-frequency } & No sound & 0.74 & 0.22 & 0.01 \\
\hline & & Unaltered & -0.01 & 0.22 & 1.00 \\
\hline & & Low-pressure & -0.13 & 0.22 & 1.00 \\
\hline & \multirow{3}{*}{ Low-pressure } & No sound & 0.87 & 0.22 & $<0.01$ \\
\hline & & Unaltered & 0.12 & 0.22 & 1.00 \\
\hline & & Low-frequency & 0.13 & 0.22 & 1.00 \\
\hline \multirow{12}{*}{ Pleased } & \multirow{3}{*}{ No sound } & Unaltered & -1.11 & 0.21 & $<0.01$ \\
\hline & & Low-frequency & -0.82 & 0.21 & $<0.01$ \\
\hline & & Low-pressure & -0.94 & 0.21 & $<0.01$ \\
\hline & \multirow{3}{*}{ Unaltered } & No sound & 1.11 & 0.21 & $<0.01$ \\
\hline & & Low-frequency & 0.30 & 0.21 & 0.90 \\
\hline & & Low-pressure & 0.18 & 0.21 & 1.00 \\
\hline & \multirow{3}{*}{ Low-frequency } & No sound & 0.82 & 0.21 & $<0.01$ \\
\hline & & Unaltered & -0.30 & 0.21 & 0.90 \\
\hline & & Low-pressure & -0.12 & 0.21 & 1.00 \\
\hline & \multirow{3}{*}{ Low-pressure } & No sound & 0.94 & 0.21 & $<0.01$ \\
\hline & & Unaltered & -0.18 & 0.21 & 1.00 \\
\hline & & Low-frequency & 0.12 & 0.21 & 1.00 \\
\hline
\end{tabular}


Table A5. Cont.

\begin{tabular}{|c|c|c|c|c|c|}
\hline Measure & & & Mean Difference & Std. Error & $p$-Value \\
\hline \multirow{12}{*}{ Restless } & \multirow{3}{*}{ No sound } & Unaltered & 0.42 & 0.21 & 0.29 \\
\hline & & Low-frequency & 0.37 & 0.21 & 0.50 \\
\hline & & Low-pressure & 0.44 & 0.21 & 0.23 \\
\hline & \multirow{3}{*}{ Unaltered } & No sound & -0.42 & 0.21 & 0.29 \\
\hline & & Low-frequency & -0.05 & 0.21 & 1.00 \\
\hline & & Low-pressure & 0.02 & 0.21 & 1.00 \\
\hline & \multirow{3}{*}{ Low-frequency } & No sound & -0.37 & 0.21 & 0.50 \\
\hline & & Unaltered & 0.05 & 0.21 & 1.00 \\
\hline & & Low-pressure & 0.07 & 0.21 & 1.00 \\
\hline & \multirow{3}{*}{ Low-pressure } & No sound & -0.44 & 0.21 & 0.23 \\
\hline & & Unaltered & -0.02 & 0.21 & 1.00 \\
\hline & & Low-frequency & -0.07 & 0.21 & 1.00 \\
\hline \multirow{12}{*}{ Sad } & \multirow{3}{*}{ No sound } & Unaltered & 0.60 & 0.18 & $<0.01$ \\
\hline & & Low-frequency & 0.44 & 0.18 & 0.08 \\
\hline & & Low-pressure & 0.38 & 0.18 & 0.19 \\
\hline & \multirow{3}{*}{ Unaltered } & No sound & -0.60 & 0.18 & $<0.01$ \\
\hline & & Low-frequency & -0.16 & 0.18 & 1.00 \\
\hline & & Low-pressure & -0.22 & 0.18 & 1.00 \\
\hline & \multirow{3}{*}{ Low-frequency } & No sound & -0.44 & 0.18 & 0.08 \\
\hline & & Unaltered & 0.16 & 0.18 & 1.00 \\
\hline & & Low-pressure & -0.06 & 0.18 & 1.00 \\
\hline & \multirow{3}{*}{ Low-pressure } & No sound & -0.38 & 0.18 & 0.19 \\
\hline & & Unaltered & 0.22 & 0.18 & 1.00 \\
\hline & & Low-frequency & 0.06 & 0.18 & 1.00 \\
\hline \multirow{12}{*}{ Rational } & \multirow{3}{*}{ No sound } & Unaltered & 0.10 & 0.22 & 1.00 \\
\hline & & Low-frequency & 0.21 & 0.22 & 1.00 \\
\hline & & Low-pressure & -0.19 & 0.22 & 1.00 \\
\hline & \multirow{3}{*}{ Unaltered } & No sound & -0.10 & 0.22 & 1.00 \\
\hline & & Low-frequency & 0.12 & 0.22 & 1.00 \\
\hline & & Low-pressure & -0.29 & 0.22 & 1.00 \\
\hline & \multirow{3}{*}{ Low-frequency } & No sound & -0.21 & 0.22 & 1.00 \\
\hline & & Unaltered & -0.12 & 0.22 & 1.00 \\
\hline & & Low-pressure & -0.41 & 0.22 & 0.38 \\
\hline & \multirow{3}{*}{ Low-pressure } & No sound & 0.19 & 0.22 & 1.00 \\
\hline & & Unaltered & 0.29 & 0.22 & 1.00 \\
\hline & & Low-frequency & 0.41 & 0.22 & 0.38 \\
\hline \multirow{12}{*}{ Responsible } & \multirow{3}{*}{ No sound } & Unaltered & 0.65 & 0.23 & 0.03 \\
\hline & & Low-frequency & 0.79 & 0.24 & 0.01 \\
\hline & & Low-pressure & 0.14 & 0.24 & 1.00 \\
\hline & \multirow{3}{*}{ Unaltered } & No sound & -0.65 & 0.23 & 0.03 \\
\hline & & Low-frequency & 0.14 & 0.24 & 1.00 \\
\hline & & Low-pressure & -0.51 & 0.23 & 0.17 \\
\hline & \multirow{3}{*}{ Low-frequency } & No sound & -0.79 & 0.24 & 0.01 \\
\hline & & Unaltered & -0.14 & 0.24 & 1.00 \\
\hline & & Low-pressure & -0.65 & 0.24 & 0.04 \\
\hline & \multirow{3}{*}{ Low-pressure } & No sound & -0.14 & 0.24 & 1.00 \\
\hline & & Unaltered & 0.51 & 0.23 & 0.17 \\
\hline & & Low-frequency & 0.65 & 0.24 & 0.04 \\
\hline
\end{tabular}


Table A6. Summary of the results of the pairwise comparisons of auditory conditions on each sensory expectation in Experiment 2 .

\begin{tabular}{|c|c|c|c|c|c|}
\hline Measure & & & Mean Difference & Std. Error & $p$-Value \\
\hline \multirow{12}{*}{ Refreshing } & \multirow{3}{*}{ No sound } & Unaltered & -0.66 & 0.17 & $<0.01$ \\
\hline & & Low-frequency & -0.43 & 0.18 & 0.09 \\
\hline & & Low-pressure & -0.64 & 0.18 & $<0.01$ \\
\hline & \multirow{3}{*}{ Unaltered } & No sound & 0.66 & 0.17 & $<0.01$ \\
\hline & & Low-frequency & 0.23 & 0.18 & 1.00 \\
\hline & & Low-pressure & 0.02 & 0.17 & 1.00 \\
\hline & \multirow{3}{*}{ Low-frequency } & No sound & 0.43 & 0.18 & 0.09 \\
\hline & & Unaltered & -0.23 & 0.18 & 1.00 \\
\hline & & Low-pressure & -0.21 & 0.18 & 1.00 \\
\hline & \multirow{3}{*}{ Low-pressure } & No sound & 0.64 & 0.18 & $<0.01$ \\
\hline & & Unaltered & -0.02 & 0.17 & 1.00 \\
\hline & & Low-frequency & 0.21 & 0.18 & 1.00 \\
\hline \multirow{12}{*}{ Sweetness } & \multirow{3}{*}{ No sound } & Unaltered & -0.27 & 0.23 & 1.00 \\
\hline & & Low-frequency & -0.19 & 0.23 & 1.00 \\
\hline & & Low-pressure & -0.36 & 0.23 & 0.74 \\
\hline & \multirow{3}{*}{ Unaltered } & No sound & 0.27 & 0.23 & 1.00 \\
\hline & & Low-frequency & 0.07 & 0.23 & 1.00 \\
\hline & & Low-pressure & -0.09 & 0.23 & 1.00 \\
\hline & \multirow{3}{*}{ Low-frequency } & No sound & 0.19 & 0.23 & 1.00 \\
\hline & & Unaltered & -0.07 & 0.23 & 1.00 \\
\hline & & Low-pressure & -0.16 & 0.23 & 1.00 \\
\hline & \multirow{3}{*}{ Low-pressure } & No sound & 0.36 & 0.23 & 0.74 \\
\hline & & Unaltered & 0.09 & 0.23 & 1.00 \\
\hline & & Low-frequency & 0.16 & 0.23 & 1.00 \\
\hline \multirow{12}{*}{ Bitterness } & \multirow{3}{*}{ No sound } & Unaltered & 0.20 & 0.24 & 1.00 \\
\hline & & Low-frequency & 0.57 & 0.25 & 0.13 \\
\hline & & Low-pressure & 0.22 & 0.25 & 1.00 \\
\hline & \multirow{3}{*}{ Unaltered } & No sound & -0.20 & 0.24 & 1.00 \\
\hline & & Low-frequency & 0.37 & 0.24 & 0.78 \\
\hline & & Low-pressure & 0.02 & 0.24 & 1.00 \\
\hline & \multirow{3}{*}{ Low-frequency } & No sound & -0.57 & 0.25 & 0.13 \\
\hline & & Unaltered & -0.37 & 0.24 & 0.78 \\
\hline & & Low-pressure & -0.35 & 0.24 & 0.91 \\
\hline & \multirow{3}{*}{ Low-pressure } & No sound & -0.22 & 0.25 & 1.00 \\
\hline & & Unaltered & -0.02 & 0.24 & 1.00 \\
\hline & & Low-frequency & 0.35 & 0.24 & 0.91 \\
\hline \multirow{12}{*}{ Refreshing } & \multirow{3}{*}{ No sound } & Unaltered & -0.66 & 0.17 & $<0.01$ \\
\hline & & Low-frequency & -0.43 & 0.18 & 0.09 \\
\hline & & Low-pressure & -0.64 & 0.18 & $<0.01$ \\
\hline & \multirow{3}{*}{ Unaltered } & No sound & 0.66 & 0.17 & $<0.01$ \\
\hline & & Low-frequency & 0.23 & 0.18 & 1.00 \\
\hline & & Low-pressure & 0.02 & 0.17 & 1.00 \\
\hline & \multirow{3}{*}{ Low-frequency } & No sound & 0.43 & 0.18 & 0.09 \\
\hline & & Unaltered & -0.23 & 0.18 & 1.00 \\
\hline & & Low-pressure & -0.21 & 0.18 & 1.00 \\
\hline & \multirow{3}{*}{ Low-pressure } & No sound & 0.64 & 0.18 & $<0.01$ \\
\hline & & Unaltered & -0.02 & 0.17 & 1.00 \\
\hline & & Low-frequency & 0.21 & 0.18 & 1.00 \\
\hline
\end{tabular}




\section{References}

1. Ritchie, H.; Roser, M. Alcohol Consumption. Our World Data. 2018. Available online: https://ourworldindata.org/alcoholconsumption (accessed on 4 July 2021).

2. Non-Alcoholic Beer Market Share, Size Global Forecast to 2030 I insightSLICE. Available online: https:/ / www.insightslice.com/ non-alcoholic-beer-market (accessed on 4 July 2021).

3. Verma, V.; Rawat, A. Non-Alcoholic Beer Market Size by Product, Technology, Sales Channel, Low Alcohol by Technology and Sales Channel, Industry Analysis Report, Regional Outlook, Growth Potential, Price Trends, Competitive Market Share E Forecast, 2017-2024; Global Market Insights: Selbyville, DE, USA, 2018; Available online: https://www.gminsights.com/industry-analysis/nonalcoholic-beer-market (accessed on 4 July 2021).

4. Attitudes towards Low- and Non-alcoholic Drink-UK-August 2019-Market Research Report. Available online: https: / / reports.mintel.com/display/919650/ (accessed on 4 July 2021).

5. IWSR Report: No- And Low-Alcohol Products Gaining Market Share. Available online: https://www.forbes.com/sites/ chrisfurnari/2021/02/09/iwsr-report-noand-low-alcohol-products-gaining-market-share/ (accessed on 4 July 2021).

6. Global Market Size of Non-Alcoholic Beer 2016-2024 I Statista. Available online: https:/ /www.statista.com/statistics/1091389/ non-alcoholic-beer-market-size-worldwide/ (accessed on 26 June 2021).

7. Update: Beer Global Market Report 2021 Including Market Size, Share \& Growth Analysis, Global Beer Consumption Statistics. Available online: https:/ /www.globenewswire.com/en/news-release/2021/04/01/2203506/0/en/Update-Beer-Global-MarketReport-2021-Including-Market-Size-Share-Growth-Analysis-Global-Beer-Consumption-Statistics.html (accessed on 26 June 2021).

8. Alcohol. Available online: https://www.who.int/health-topics/alcohol\#tab=tab_1 (accessed on 4 July 2021).

9. Sohrabvandi, S.; Mousavi, S.M.; Razavi, S.H.; Mortazavian, A.M.; Rezaei, K. Alcohol-free Beer: Methods of Production, Sensorial Defects, and Healthful Effects. Food Rev. Int. 2010, 26, 335-352. [CrossRef]

10. Silva, A.P.; Jager, G.; van Bommel, R.; van Zyl, H.; Voss, H.P.; Hogg, T.; Pintado, M.; de Graaf, C. Functional or emotional? How Dutch and Portuguese conceptualise beer, wine and non-alcoholic beer consumption. Food Qual. Prefer. 2016, 49, 54-65. [CrossRef]

11. Silva, A.P.; Jager, G.; Voss, H.P.; van Zyl, H.; Hogg, T.; Pintado, M.; de Graaf, C. What's in a name? The effect of congruent and incongruent product names on liking and emotions when consuming beer or non-alcoholic beer in a bar. Food Qual. Prefer. 2017, 55, 58-66. [CrossRef]

12. Blackmore, H.; Hidrio, C.; Godineau, P.; Yeomans, M.R. The effect of implicit and explicit extrinsic cues on hedonic and sensory expectations in the context of beer. Food Qual. Prefer. 2020, 81, 103855. [CrossRef]

13. Spence, C. Sound Design: Using Brain Science to Enhance Auditory \& Multisensory Product \& Brand Development. In $(((A B A)))$ Audio Branding Academy Yearbook 2010/2011; Nomos Verlagsgesellschaft mbH \& Co. KG: Baden, Germany, 2013 ; pp. 33-51.

14. Sensory Experiences Increase In-Store Sales by 10 Percent, Finds New Research from Mood Media. Available online: https: //www.businesswire.com/news/home/20191112005413/en/Sensory-Experiences-Increase-In-Store-Sales-10-Percent (accessed on 4 July 2021).

15. Wang, Q.J.; Spence, C. Sonic Packaging: How Packaging Sounds Influence Multisensory Product Evaluation. In Multisensory Packaging; Springer International Publishing: Cham, Switzerland, 2018; pp. 103-125.

16. Spence, C.; Wang, Q. Sensory expectations elicited by the sounds of opening the packaging and pouring a beverage. Flavour 2015, 4, 35. [CrossRef]

17. Almiron, P.; Escobar, F.B.; Pathak, A.; Spence, C.; Velasco, C. Searching for the sound of premium beer. Food Qual. Prefer. 2021, 88, 104088. [CrossRef]

18. Komatsuzaki, T.; Han, J.; Uchida, H. Approach for combining physical properties and sensibility for pleasant beverage canopening sound. Appl. Acoust. 2016, 103, 64-70. [CrossRef]

19. Bleier, R.; Fischer, F.; Hiltmann, T.; Viehhauser, G.; Vogeler, G. Digitale Mediävistik und der deutschsprachige Raum. Das Mittelalt. 2019, 24, 1-12. [CrossRef]

20. Ringler, C.; Sirianni, N.J.; Christenson, B. The Power of Consequential Product Sounds. J. Retail. 2021, 97, 288-300. [CrossRef]

21. Velasco, C.; Obrist, M.; Petit, O.; Spence, C. Multisensory Technology for Flavor Augmentation: A Mini Review. Front. Psychol. 2018, 9, 26. [CrossRef]

22. Fiore, S.G.; Kelly, S. Surveying the use of sound in online stores: Practices, possibilities and pitfalls for user experience. Int. J. Retail. Distrib. Manag. 2007, 35, 600-611. [CrossRef]

23. Petit, O.; Velasco, C.; Spence, C. Digital Sensory Marketing: Integrating New Technologies Into Multisensory Online Experience. J. Interact. Mark. 2019, 45, 42-61. [CrossRef]

24. Hwang, A.H.-C.; Oh, J.; Scheinbaum, A.C. Interactive music for multisensory e-commerce: The moderating role of online consumer involvement in experiential value, cognitive value, and purchase intention. Psychol. Mark. 2020, 37, 1031-1056. [CrossRef]

25. Mobile: The Closest You Can Get to Your Consumers. Available online: https://www.mmaglobal.com/case-study-hub/case_ studies/view/56399 (accessed on 27 July 2021).

26. Desmet, P. Designing Emotions. Ph.D. Thesis, Department of Industrial Design, Delft University of Technology, Delft, The Netherlands, 2002. 
27. Özcan, E.; Van Egmond, R.; Jacobs, J.J. Product sounds: Basic concepts and categories. Int. J. Des. 2014, 8, 97-111.

28. Özcan, E.; van Egmond, R. Basic Semantics of Product Sounds. Int. J. Des. 2012, 6, 41-54.

29. Velasco, C.; Salgado-Montejo, A.; Marmolejo-Ramos, F.; Spence, C. Predictive packaging design: Tasting shapes typefaces, names, and sounds. Food Qual. Prefer. 2014, 34, 88-95. [CrossRef]

30. Simner, J.; Cuskley, C.; Kirby, S. What Sound Does That Taste? Cross-Modal Mappings across Gustation and Audition. Perception 2010, 39, 553-569. [CrossRef]

31. Roque, J.; Lafraire, J.; Auvray, M. Audiovisual Crossmodal Correspondence between Bubbles' Size and Pouring Sounds' Pitch in Carbonated Beverages. Foods 2020, 9, 966. [CrossRef] [PubMed]

32. Bleier, A.; Harmeling, C.M.; Palmatier, R.W. Creating Effective Online Customer Experiences. J. Mark. 2018, 83, 98-119. [CrossRef]

33. Friedman, H. Simplified Determinations of Statistical Power, Magnitude of Effect and Research Sample Sizes. Educ. Psychol. Meas. 1982, 42, 521-526. [CrossRef]

34. Tijssen, I.; Zandstra, E.H.; de Graaf, C.; Jager, G. Why a ‘light' product package should not be light blue: Effects of package colour on perceived healthiness and attractiveness of sugar- and fat-reduced products. Food Qual. Prefer. 2017, 59, 46-58. [CrossRef]

35. Huang, L.; Lu, J. The Impact of Package Color and the Nutrition Content Labels on the Perception of Food Healthiness and Purchase Intention. J. Food Prod. Mark. 2015, 22, 191-218. [CrossRef]

36. Huang, L.; Lu, J. Eat with Your Eyes: Package Color Influences the Perceptions of Food Taste and Healthiness Moderated by External Eating. Mark. Manag. 2015, 25, 71-87.

37. Wang, Q.J.; Spence, C. The Role of Pitch and Tempo in Sound-Temperature Crossmodal Correspondences. Multisens. Res. 2017, 30, 307-320. [CrossRef]

38. Desira, B.; Watson, S.; Van Doorn, G.; Timora, J.; Spence, C. Happy Hour? A Preliminary Study of the Effect of Induced Joviality and Sadness on Beer Perception. Beverages 2020, 6, 35. [CrossRef]

39. Reinoso-Carvalho, F.; Dakduk, S.; Wagemans, J.; Spence, C. Not Just Another Pint! The Role of Emotion Induced by Music on the Consumer's Tasting Experience. Multisens. Res. 2019, 32, 367-400. [CrossRef] [PubMed]

40. Peng-Li, D.; Mathiesen, S.L.; Chan, R.C.K.; Byrne, D.V.; Wang, Q.J. Sounds Healthy: Modelling sound-evoked consumer food choice through visual attention. Appetite 2021, 164, 105264. [CrossRef] [PubMed]

41. Biswas, D.; Lund, K.; Szocs, C. Sounds like a healthy retail atmospheric strategy: Effects of ambient music and background noise on food sales. J. Acad. Mark. Sci. 2018, 47,37-55. [CrossRef]

42. Spence, C.; Velasco, C. Packaging Colour and Its Multiple Roles. In Multisensory Packaging; Springer International Publishing: Cham, Switzerland, 2018; pp. 21-48.

43. Müller, M.; Bellut, K.; Tippmann, J.; Becker, T. Physikalische Verfahren zur Entalkoholisierung verschiedener Getränkematrizes und deren Einfluss auf qualitätsrelevante Merkmale. Chem. Ing. Tech. 2016, 88, 1911-1928. [CrossRef]

44. Madjid, R. The influence store atmosphere towards customer emotions and purchase decisions. Int. J. Humanit. Soc. Sci. Invent. 2014, 3, 11-19.

45. Bagozzi, R.P.; Belanche, D.; Casaló, L.V.; Flavián, C. The Role of Anticipated Emotions in Purchase Intentions. Psychol. Mark. 2016, 33, 629-645. [CrossRef] 